Sharif University of Technology
Scientia Iranica
Transactions E: Industrial Engineering
hCIENTIA

\title{
A new bi-objective integrated vehicle transportation model considering simultaneous pick-up and split delivery
}

\author{
N. Akbarpour ${ }^{a}$, R. Kia ${ }^{b}$, and M. Hajiaghaei-Keshteli ${ }^{a}, *$ \\ a. Department of Industrial Engineering, University of Science and Technology of Mazandaran, Behshahr, Iran. \\ b. Department of Logistics, Tourism \& Service Management, Faculty of Business \& Economics, German University of Technology \\ in Oman (GUtech), Muscat, Oman.
}

Received 21 February 2019; received in revised form 4 December 2019; accepted 18 February 2020

\author{
KEYWORDS \\ Vehicle routing \\ problem; \\ Simultaneous pick-up \\ and split delivery; \\ Production planning; \\ Integration; \\ Mixed-integer \\ programming.
}

\begin{abstract}
Nowadays, global competition urges companies to more seriously consider the issue of cost reduction and high productivity in business networks. In this context, today, both industrial practitioners and researchers are focusing on the issues underlying the supply chain structure. In order to materialize real-world objectives, this study aims to improve the performance of the supply chain network by considering simultaneous pickup and split delivery, minimizing total costs, and maximizing customer services within a multi-period multi-product production planning. Besides, relevant data of the involved parameters were collected upon investigating a case study of a food industry located north of Iran. Eventually, the proposed mixed-integer linear programming model was addressed using a $\varepsilon$-constraint method. Finally, related results of this solution were analyzed and compared with those of simple Vehicle Routing Problem (VRP).
\end{abstract}

(C) 2021 Sharif University of Technology. All rights reserved.

\section{Introduction and literature review}

Structure of supply chain arrangement is complex and is always characterized by myriad merits diffusing over numerous functions and settings. Besides, one may define logistics as a method that determines the right quantity of certain commodities at the right time and place; thus, this method is recommended for dealing with supply chain network problems [1]. A problem arises when the supplies of service industries are asked to be allocated or applied in an efficient

\footnotetext{
*. Corresponding author.

E-mail addresses: N.Akbarpour@mazust.ac.ir(N. Akbarpour); reza.kia@gutech.edu.om (R. Kia); mostafahaji@mazust.ac.ir (M. Hajiaghaei-Keshteli)
}

way. This usually happens since the service industries must consider the transportation route and improve the vehicle loading rate [2].

The mean shipping expense in Iran ranges between 1.7 and 2 times that of the international average based on the report announced by the Iran Chamber of Commerce Industries, Mines, and Agriculture and the World Bank, as shown in Figures 1-3 [3]. Therefore, for modern companies to survive and remain active in the global competitive arena, adoption of innovate methods to enhance logistics and distribution activities to satisfy customer demands and reduction of production cost are highly recommended [4].

The purpose of traditional Vehicle Routing Problem (VRP) is to determine short-distance itineraries in order to visit a number of dispersed customers by carrier machines such that the capacity of each carrier machine be considered and every client be met 


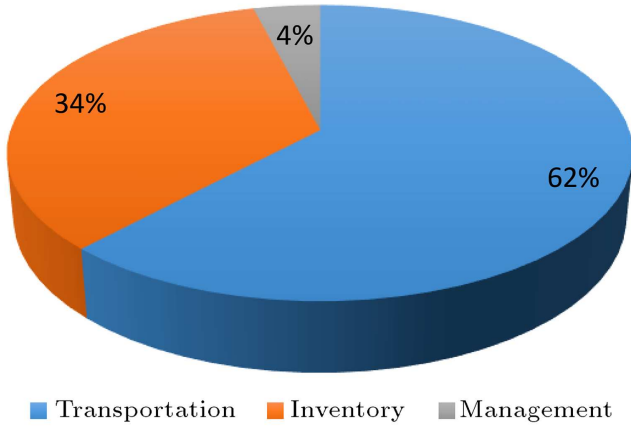

Figure 1. The share of the costs for each sector of logistics.

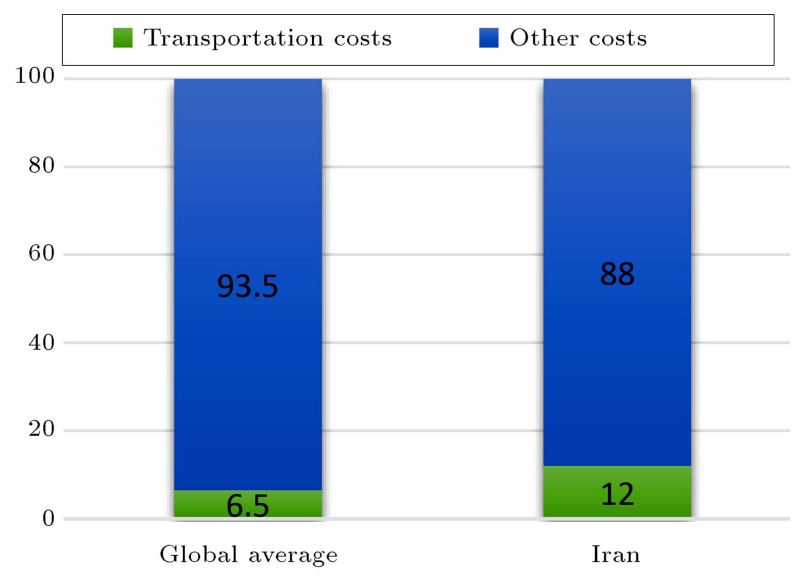

Figure 2. Percentage of the price of finished products.

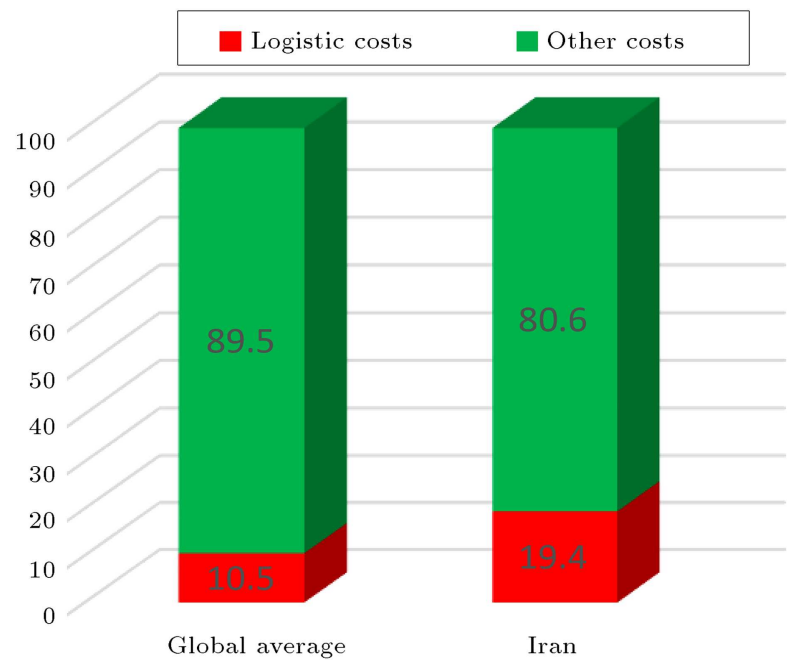

Figure 3. Percentage of the price of finished products.

once. Moreover, there are three different groups to categorize the attributes of the distribution manner: Warehousing, cross-docking, and direct shipping. Here, authors seek to briefly define the purpose of the mentioned terms: Warehousing is needed and, thus, the stock could pile up with goods and be transferred to customers when the need arises. Cross-docking reduces the need for large stocks using a conveyance procedure called just-in-time, and direct shipping is used to distribute goods directly from suppliers to customers [5].

Many researchers have sought to consider distribution planning and integrated production under the supply chain structure over the past few years. Some researchers claim that two principal causes are responsible for integrating production and distribution planning: (a) the desirable aspect of the increase in income in the supply chain and (b) plus points on a decrease in lead times and showing prompt responses to trade changes [6,7]. Similarly, some studies point out that the integration of production and distribution planning may lead to (a) a reduction in the expense of operating and implementing a production-distribution method and (b) more effective fulfilling of the buyer's order $[8-10]$.

Liu and Papageorgiou [11] presented a mathematical model for production, distribution, and capacity planning in a global supply chain. In this paper, three objectives involving total expenses, lost sales, and flow time alongside two strategies extending the manufacturing capacity were assumed. The core of systematic scattering is VRP. Thousands of corporations performing different activities and occupations such as collecting, shipment, conveyance, and manufacturing have been always dealing with this issue. Since conditions differ from one system to another, the objectives and constraints of the VRP are very diverse.

VRP was first proposed by Dantzig and Ramser [12]. A case study involving the distribution of gasoline from a terminal to a vast number of customers was adopted. This study utilized the issue of Euclidean distance in traditional VRP; nevertheless, this assumption is in contrast with the real road conditions. Upon considering this assumption, estimated expenses are greater than the real ones, because the expenses related to the traveling time are ignored. In a model presented by Polimeni and Vitetta [13], the total time required for vehicles to visit nodes including clients and warehouses is dependent on not only the distance among clients but also the time of the day when vehicles move; in this way, real situations such as weather conditions and traffic jams (the velocity of the fleet depends on travel speed) are taken into account as affecting factors. Besides, the cumulative capacitated vehicle routing problem was proposed by Ozsoydan and Sipahioglu [14]. In this paper, authors do not consider the whole tour cost of the supply chain; instead, they would like to minimize the whole arrival times to points (clients and depots). Following certain time events such as natural disasters, this type of routing issue is popular because momentous commodity delivery is of high priority. Although considering a single depot in the VRP remains interesting and simple up until now, corporations having more than one depot need a 
new model. Bertazzi and Speranza [15] introduced a model that was formulated by making some alteration in the classic inventory shipping model. First, this model begins with a vehicle responsible for transferring commodities. Then, a lot of vehicles are added to the previous fleet. Allahyari et al. [16] focused on a model called multi-depot VPR in which each depot is responsible for a cluster of determined customers and each vehicle comes back to the same initial depot.

Baldacci et al. [17] expressed other VRP applications such as food delivery, web connections, letterboxes distribution, and waste collection planning. Moreover, Golmohamadi et al. [18] proposed a model in which commodities were shipped in boxes in a constant expense transportation problem. In another study, Fathollahi-Fard et al. [19] developed and coordinated the integrated shipping and production scheming issue with time windows and due date time to minimize the total cost. In traditional VRP, the final phase of a supply chain deals with product delivery. Although goods should be picked up and delivered, Vehicle Routing Problem with Simultaneous Pick-up and Delivery (VRPSPD) as a type of VRP was presented by Min [20] for the first time. Salhi and Nagy [21] designed a new model for a shipping organization that utilized many types of VRPs. A number of depots and Distribution Centers (DCs) were added to the previous study of Nagy and Salhi to extend it [22]. Dethloff [23] investigated a model that incorporated reverse logistics in a VRPSPD and then, studied the connection between VRPSPD and other shipping issues. Gendreau et al. [24] developed a transportation shipping problem when they received dynamic requests from their clients. In the following, a model considered the time window for VRPSPD, as presented by Wang and Chen [25]. The VRPSPD model with non-homogeneous vehicles was introduced by Avci and Topaloglu [26] who solved it using metaheuristic algorithm. In another study, Majidi et al. [27] demonstrated that a pollution routing problem was discussed using simultaneous pickup and delivery. The authors declared that the objectives considered for this problem entailed minimizing fuel consumption and emissions as well as using scheduling and routing customers. A different version of VRP considering pick-up conditions was expanded by Ting et al. [28]. This innovation method was formulated based on the shortest optimal path from one point (depots and clients) to another as well as ordinary constraints such as fleet volume and length of the path. Recently, such new and novel subjects were added to VRP and discussed by Wang and Li [29] and Matos et al. [30]. They focused on green supply chain and routing issues with the aim of minimizing pollutions including carbon emissions. Abad et al. [31] proposed a bi-objective mathematical programming model. The authors sought to consider consolidation approaches to cross-dock problems and to coordinate VRP with the integration of delivery and pick-up. Shi et al. [32] considered a Home Health Care (HHC) shipping issue with stochastic service times and traveling with regard to the logistics practice of HHC corporates.

In most VRPs, one of the significant hypotheses is the fleet visiting each customer just one time. This is not always a realistic assumption because customer demand sometimes takes over the vehicle's volume. Therefore, the constraint that encourages this assumption is partly resolved in this paper. As a result, a customer could be met by several transportation vehicles. Split Delivery Vehicle Routing Problem (SDVRP) was first defined by Dror and Trudeau [33]. Besides, Archetti et al. [34] demonstrated that the application of this method kept the traveled distance up to $50 \%$. Transferring products to customers using SDVRP may often yield two kinds of dilemma: interference and additional jobs. To overcome this, Gulczynaski et al. [35] introduced Split Delivery Vehicle Routing Problem with Minimum Delivery Amounts (SDVRP-MDA) model for the first time. In this model, the minimum predetermined requests containing up to $50 \%$ of buyer requests are shipped in each meeting, resulting in minor disorder and difficulty. Moreover, Archetti's SDVRP format was changed into SDVRPMDA by Han and Chu [36] and an innovation heuristic approach was presented. A mathematical model with a bi-objective function and the unique kind of split deliveries were proposed by Xia et al. [37]. Moreover, the only way to split the customer's request is to divide it by backpack and the innovation heuristic algorithm like Tabu search was suggested for solving the problem. Hernández-Pérez et al. aimed to minimize the cost associated with the capacitated vehicle problem [38]. They addressed this problem by proposing a model through the optimization of goods transportation among an array of buyers. They allowed two new and infrequent characteristics in the pickup and delivery fields. The first characteristic was related to the number of customer visits. In fact, buyers may be met many times. Besides, in the second one, buyer turns to the temporary and middle locations to collect and deliver products. Qiu et al. [39] proposed a model named Vehicle Routing Problem with Discrete Split Deliveries and Pickups (VRPDSDP) and designed a TS algorithm with a batch mixture and item initiating function. Abdi et al. [40] introduced a new effective VRP model to reduce the total cost of the proposed network. The model considers not only greenness but also other environmental factors. The model was solved using some meta-heuristics. The problem of using Vendor Managed Inventory (VMI) policy with perishable products was addressed by Amiri et al. [41]. The authors designed a two-echelon supply 
chain network and utilized multiple meta-heuristics to resolve the issue.

Fathollahi-Fard et al. $[42,43]$ presented a biobjective location-allocation-distribution model for HHC logistics services in which caregivers plan goods delivery from a pharmacy to homes of sick people and also, deliver products to diverse care services. Finally, caregivers resort to their lab to enhance the health status of the sick. Moreover, the above authors employed heuristics and a hybrid constructive metaheuristic in their paper. Feng et al. [44] optimized hybrid disassembly and proposed end-of-life processes of commodity improvement, maximized the benefits of this improvement, and minimized possible side effects. They dealt with the operation planning and end-of-life decision-making issues for commodity improvement. Tian et al. $[45,46]$ presented an innovative graph-based disassembly sequence planning with emphasis on the uncertain element quality and varying disassembly operational expenses. However, these papers presented an innovative hybrid intelligent algorithm that integrated fuzzy simulation with artificial bee colony to resolve the problem. Fu et al. [47] addressed a two-agent stochastic flow shop deteriorating scheduling problem with the objectives of minimizing the makespan of the first agent and the total tardiness of the second agent. Then, they used a hybrid multi-objective evolutionary algorithm to solve it. Fu et al. [48] proposed sustainable and effective production operations and the scheduling model so as to facilitate an interplay between the manufacturing expense and energy consumption.

The papers reviewed above had investigated the discussed VRP problems merely in the context of supply chain. Objective functions of transportation models are as follows:

(a) Minimizing the number of fleets needed to give service to the buyers;

(b) Stabilizing the journey in terms of traveling time and vehicle load;

(c) Considering the deadline of the agreement and being cautious about earliness and tardiness;

(d) Minimizing the whole journey length.

In this paper, a VRP problem is extended to ensure better supply chain efficiency. Using the aforementioned cases and literature reviews, one can infer that simultaneous pick-up and delivery issues and also split delivery issues are studied separately. To the best of our knowledge, only a few papers have reported these two separate issues. Thus, this raises an important aspect of our study which is the necessity to integrate the pre-mentioned decisions and considerations. Accordingly, we propose an innovative formulation that aims to detect the best track in terms of reducing traveling space and the number of fleets

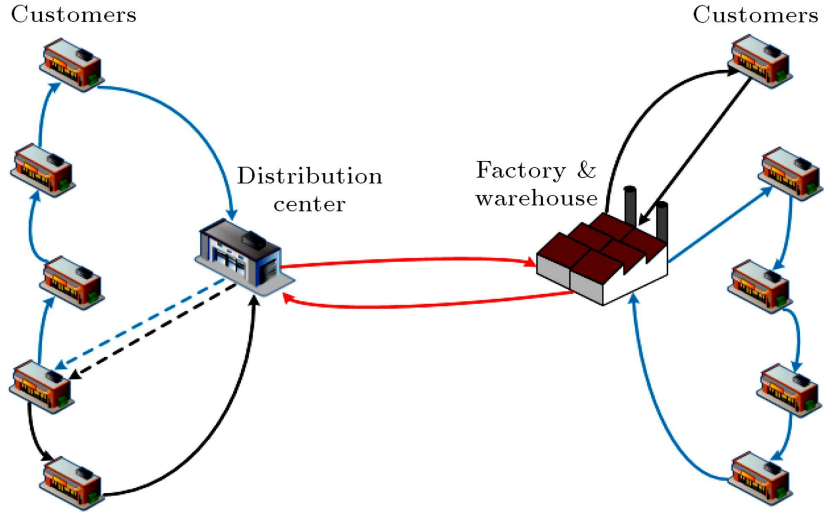

Figure 4. The schematic of material flow.

needed to dispatch goods from DCs to buyers. In addition, production planning is another significant decision on optimization that determines the amount of plant production within a certain time horizon, amount of inventory in the plant, lost sales for each buyer, and the dispatching point. Also, by using an $\varepsilon$-constraint via the GAMS, the mathematical model is solved.

The contributions of this study based on the top experts' comments are summed up in the following bullet points:

- As seen in Figure 4, both warehousing and direct shipping for dispatching are considered;

- A bi-objective simultaneous pick-up and split delivery VRP mathematical model is developed with emphasis on the multi-period multi-product production planning;

- The role of production planning in the VRP problem is considered to expand a practical framework of organized operations at the same time.

The next sections are structured as follows. Section 2 elaborates a framework for the problem and describes the objective function and the mathematical model. Section 3 presents a numerical example, validation, computerized results, and sensitivity analysis. Finally, Section 4 concludes the paper.

\section{The problem formulation and explanations}

Figure 4 depicts the framework of the introduced supply chain structure in this paper. The integrated planning of shipping and production is simultaneously conducted in this system. As shown, a plant warehouse and a DC are considered.

The aim of this research is to determine the best quantity of output commodities, inventories of each product in the warehouse and DC in the planning horizon, and vehicle routing in supply chain network with emphasis on reducing transportation costs and increasing customer satisfaction which can be translated into 
reduced number of lost sales. The objective function includes the production, distribution, and inventory holding costs, constituting the total cost of the chain.

This study takes into account some significant features of routing and production including:

(a) The number of demands for multi-commodities in the scheming horizon;

(b) Constant and floating charge of manufacturing;

(c) Capacity peak of manufacturing plants;

(d) Constant charge of routing incurred on each track utilized in the solution as well as the floating charge of routing adequate to both the total number of goods on the fleet and traveled distance;

(e) The peak capacity of the fleet;

(f) The quantity of picked-up commodities;

(g) The quantity of inventory;

(h) The peak capacity of warehouse and DC.

\section{Significant assumptions:}

- Lost sales occur when customer demands are unsatisfied and the model functionality is not delayed in terms of satisfying the mentioned demands;

- Both warehousing and direct shipping for sharing are considered;

- Each vehicle is a member of either warehouse or DC; they begin and finish at the same point;

- Buyers including the fleet are assigned to either the DC or warehouse.

In the following, the mathematical model formulation is detailed out:

\section{Indices}

$j, j^{\prime} \in\{1,2, \cdots, J\}$ Index of buyers allocated to DC

$k, k^{\prime} \in\{1,2, \cdots, K\}$ Index of buyers allocated to the warehouse

$n \in\{1,2, \cdots, N\}$ Index of fleet allocated to DC

$m \in\{1,2, \cdots, M\}$ Index of fleet allocated to the warehouse

$p \in\{1,2, \cdots, P\} \quad$ Index of commodity

$t \in\{1,2, \cdots, T\} \quad$ Index of time period

\section{Parameters}

$U \quad$ Large amount

$a_{p} \quad$ Size of commodity $p$

$V_{m} \quad$ The volume of fleet $m$

$V_{n}^{\prime} \quad$ The volume of fleet $n$

$F C_{m t} \quad$ Constant charge of applied fleet $m$ at time $t$
$F C_{n t}^{\prime} \quad$ Constant charge of applied fleet $n$ at time $t$

$d s_{k} \quad$ Space between the factory and buyer $k$

$d s_{j}^{\prime} \quad$ Space between DC and buyer $j$

$d i_{k k^{\prime}} \quad$ Space between buyers $k$ and $k^{\prime}$

$d i_{j j^{\prime}} \quad$ Space between buyers $j$ and $j^{\prime}$

$C_{p m} \quad$ Charge of shipping between the factory and DC via fleet $m$ per unit of commodity $p$

$C W_{p n j}^{\prime} \quad$ Charge of delivery between DC and buyer $j$ via fleet $n$ per unit of commodity $p$

$C W_{p n j j^{\prime}}^{\prime \prime} \quad$ Charge of shipping between buyer $j$ and buyer $j^{\prime}$ via fleet $n$ per unit of commodity $p$

$C E_{p m k}^{\prime} \quad$ Charge of shipping between the factory and buyer $k$ via fleet $m$ per unit of commodity $p$

$C E_{p m k k^{\prime}}^{\prime \prime} \quad$ Charge of shipping between buyer $k$ and buyer $k^{\prime}$ via fleet $m$ per unit of commodity $p$

$I C_{p t} \quad$ Charge of inventory in the warehouse per unit of commodity $p$ at time $t$

$I C_{p t}^{\prime} \quad$ Charge of inventory at DC per unit of commodity $p$ at time $t$

$I N V_{\max } \quad$ The peak of the warehouse volume

$I N V_{\max }^{\prime} \quad$ The peak of DC volume

$C A P_{p t} \quad$ Volume of production for commodity $p$ at time $t$

$D_{p k t} \quad$ The quantity of commodities $p$ at time $t$ demanded by buyer $k$

$D_{p j t}^{\prime} \quad$ The quantity of commodities $p$ at time $t$ demanded by buyer $j$

$P_{p k t} \quad$ The quantity of commodities $p$ at time $t$ which is picked up by buyer $k$

$P_{n j t}^{\prime} \quad$ The quantity of commodities $P$ at time $t$ which is picked up by buyer $j$

$F F C_{p t} \quad$ Constant production charge of commodity $p$ at time $t$

$V F C_{p} \quad$ The floating charge of commodity $p$

\section{Integer and binary variables}

$Q D_{p m t}$

The quantity of the commodities $p$ via fleet $m$ at time $t$ transferred from the warehouse to DC

$Q P_{p m t} \quad$ The quantity of the picked up commodities $p$ via fleet at time $t$ transferred from the DC to the warehouse $m$

$Q W D_{p n j t}^{\prime} \quad$ The quantity of the commodities $p$ via fleet $n$ at $t$ transferred from DC to buyer $j$ 
$Q W P_{\text {pnjt }}^{\prime} \quad$ The quantity of the commodities $p$ via fleet $n$ at time $t$ picked up by buyer $j$

$Q W P_{p n j j^{\prime} t}^{\prime \prime}$ The quantity of the commodities $p$ at time $t$ via fleet $n$ picked-up of the buyer $j^{\prime}$ when the fleet transferred from buyer $j$ to buyer $j^{\prime}$

$Q W D_{p n j j^{\prime} t}^{\prime \prime}$ The quantity of the commodities $p$ at time $t$ via fleet $n$ transferred from buyer $j$ to buyer $j^{\prime}$

$Q E D_{p m k t}^{\prime} \quad$ The quantity of the commodities $p$ at time $t$ via fleet $m$ transferred from the warehouse to buyer $k$

$Q E P_{p m k t}^{\prime} \quad$ The quantity of the commodities $p$ at time $t$ via fleet $m$ picked up by buyer $k$

$Q E P_{p m k k^{\prime} t}^{\prime \prime}$ The quantity of the commodities $p$ at time $t$ via fleet $m$ picked up by buyer $k^{\prime}$ when the fleet transferred from buyer $k$ to buyer $k^{\prime}$

$Q E D_{p m k k^{\prime} t}^{\prime \prime}$ The quantity of the commodities $p$ at time $t$ via fleet $n$ transferred from buyer $k$ to buyer $k^{\prime}$

$L_{\text {pnjt }}^{\prime} \quad$ The quantity of the commodities $p$ remaining on fleet $n$ instantly after transferring to buyer $j$ at time $t$

$L_{p m k t} \quad$ The quantity of the commodities $p$ remaining on fleet $m$ instantly after transferring to buyer $k$ at time $t$

$L_{0 p m t} \quad$ The quantity of the commodities $p$ at time $t$ in the warehouse put on fleet $m$

$L_{0 p n t}^{\prime}$

$L P_{p j t}^{\prime}$ The quantity of the commodities $p$ at time $t$ in DC put on fleet $n$

The quantity of the commodities $p$ at time $t$ delivered back to the warehouse of DC

$L P_{p k t} \quad$ The quantity of the commodities $p$ at time $t$ delivered back to the warehouse picked up by all buyers allocated to DC

$I N V_{p t} \quad$ Inventory level of commodity $p$ in the warehouse at the end of time $t$

$I N V_{p t}^{\prime} \quad$ Inventory level of commodity $p$ in DC at the end of time $t$

$L S_{p j t}^{\prime} \quad$ Lost sale amount of commodity $p$ at time $t$ to buyer $j$

$L S_{p k t} \quad$ Lost sale amount of commodity $p$ at time $t$ to buyer $k$

$L P_{p t} \quad$ The quantity of commodities $p$ manufactured at time $t$

$Y_{m t} \quad\{1$; if fleet $m$ at time $t$ moves to DC from the warehouse. 0; otherwise $\}$

$Y W_{n j t}^{\prime} \quad\{1$; if fleet $n$ at time $t$ moves to buyer $j$ from DC. 0 ; otherwise $\}$
$Y W_{n j j^{\prime} t}^{\prime \prime} \quad\{1$; if fleet $n$ at time $t$ moves to buyer $j^{\prime}$ from buyer $j$. 0 ; otherwise $\}$

$Y W_{n j t} \quad\{1$; if fleet $n$ at time $t$ moves to DC from buyer $j$. 0 ; otherwise

$Y E_{m k t}^{\prime} \quad\{1$; if fleet $m$ at time $t$ moves to buyer $k$ from the warehouse. 0 ; otherwise

$Y E_{m k k^{\prime} t}^{\prime \prime} \quad\{1$; if fleet $m$ at time $t$ moves to buyer $k^{\prime}$ from buyer $k$. 0 ; otherwise $\}$

$Z E_{m k t} \quad\{1$; if fleet $m$ at time $t$ moves to the warehouse from buyer $k$. 0; otherwise

$W_{p t} \quad\{1$; if commodity $p$ at time $t$ is

Model: produced. 0 ; otherwise $\}$

$\min Z_{1}=W P E+W S E+W I E$,

$W P E=\sum_{p} \sum_{t} F F C_{p} \cdot W_{p t}+\sum_{p} \sum_{t} V F C_{p} \cdot A P_{p t}$

$W S E=\sum_{m} \sum_{t} F C_{m} \cdot Y_{m t}+\sum_{m} \sum_{k} \sum_{t} F C_{m} \cdot Y E_{m k t}^{\prime}$

$+\sum_{n} \sum_{j} \sum_{t} F C_{n}^{\prime} \cdot Y W_{n j t}^{\prime}$

$+\sum_{m} \sum_{k} \sum_{t} d s_{k} \cdot Y E_{m k t}^{\prime}$

$+\sum_{n} \sum_{j} \sum_{t} d s_{j}^{\prime} \cdot Y W_{n j t}^{\prime}$

$+\sum_{m} \sum_{k \neq k^{\prime}} \sum_{k^{\prime}} \sum_{t} d i_{k k^{\prime}} \cdot Y E_{m k k^{\prime} t}^{\prime \prime}$

$+\sum_{n} \sum_{j \neq j^{\prime}} \sum_{j^{\prime}} \sum_{t} d i_{j j^{\prime}}^{\prime} \cdot Y W_{n j j^{\prime} t}^{\prime \prime}$

$+\sum_{p} \sum_{m} \sum_{t} C_{p m} \cdot Q D_{p m t}$

$+\sum_{p} \sum_{n} \sum_{j} \sum_{t} C W_{p n j t}^{\prime} \cdot Q W D_{p n j t}^{\prime}$

$+\sum_{p} \sum_{n} \sum_{j \neq j^{\prime}} \sum_{j^{\prime}} \sum_{t} C W_{p n j j^{\prime}}^{\prime \prime} \cdot Q W D_{p n j j^{\prime} t}^{\prime \prime}$

$+\sum_{p} \sum_{m} \sum_{k} \sum_{t} C E_{p m k}^{\prime} \cdot Q E D_{p m k t}^{\prime}$

$+\sum_{p} \sum_{m} \sum_{k \neq k^{\prime}} \sum_{k^{\prime}} \sum_{t} C E D_{p m k k^{\prime}}^{\prime \prime} \cdot Q E D_{p m k k^{\prime} t}^{\prime \prime}$

$W I E=\sum_{p} \sum_{t} I C_{p t} \cdot \operatorname{In} v_{p t} \cdot+\sum_{p} \sum_{t} I C_{p t}^{\prime} \cdot \operatorname{In} v_{p t}^{\prime}$, 


$$
\begin{aligned}
\min Z_{2}= & \sum_{p} \sum_{k} \sum_{t} L S_{p k t}+\sum_{p} \sum_{j} \sum_{t} L S_{p j t}^{\prime} \\
& +\sum_{p} \sum_{k} \sum_{t} L P_{p k t}+\sum_{p} \sum_{j} \sum_{t} L P_{p j t}^{\prime} .
\end{aligned}
$$

The first objective function $Z_{1}$ consists of three components to be described in the following.

Element (1.1) shows the Whole Production Expenses (WPE) composed of the constant as well as floating charge of production for the commodities in the planning horizon. Element (1.2) shows the Whole Shipping Expenses (WSE) composed of constant track expenses for transferring the fleet, the floating shipping expenses as the cause of fuel consumption and fleet depreciation relevant to the traveled length by the fleet and the quantity of shipped commodities. Element (1.3) shows the Whole Inventory Expenses (WIE) composed of holding expenses of commodities. Another target is $Z_{2}$ consisting of the whole quantity of returned commodities called lost sales.

Subject to:

$$
\begin{array}{ll}
\sum_{p} Q W P_{p n j t}^{\prime} \leq U \cdot Y W_{n j t}^{\prime}, & \forall n, j, t, \\
\sum_{p} Q E P_{p m k t}^{\prime} \leq U \cdot Y E_{m k t}^{\prime}, & \forall m, k, t .
\end{array}
$$

In Constraints (3) and (4), the pick-up condition for buyers $j$ and $k$ is that the fleets $n$ and $m$ travel from DC and the warehouse to buyers $j$ and $k$.

Constraints (5) and (6) are similar to earlier constraints with a minor difference that the fleet must visit another buyer before visiting any new buyer:

$$
\begin{aligned}
& \sum_{p} Q W P_{p n j j^{\prime} t}^{\prime \prime} \leq U \cdot Y W_{n j j^{\prime} t}^{\prime \prime}, \\
& \forall n, j, j^{\prime}\left(j \neq j^{\prime}\right), t, \\
& \sum_{p} Q E P_{p m k k^{\prime} t}^{\prime \prime} \leq U \cdot Y E_{m k k^{\prime} t}^{\prime \prime}, \\
& \forall m, k, k^{\prime}\left(k \neq k^{\prime}\right), t .
\end{aligned}
$$

Constraint (7) shows the condition for the transfer from the warehouse to DC. Besides, we should consider the maximum fleet volume:

$$
\sum_{p} a_{p} \cdot Q D_{p m t} \leq V_{m} \cdot Y_{m t}, \quad \forall m, t .
$$

Constraints (8) and (9) state the capacity condition of the fleet upon the decision to transfer commodities:

$$
\sum_{p} L_{0 p n t}^{\prime} \cdot a_{p} \leq V_{n}^{\prime}, \quad \forall n, t,
$$

$$
\sum_{p} L_{0 p m t} \cdot a_{p} \leq V_{m}, \quad \forall m, t .
$$

Constraints (10) and (11) are similar to Constraints (8) and (9) with a difference that Constraints (8) and (9) begin from depots while the former constraints visit other buyers before visiting the new ones:

$$
\begin{array}{ll}
\sum_{p} L_{p n j t}^{\prime} \cdot a_{p} \leq V_{n}^{\prime}, & \forall n, j, t, \\
\sum_{p} L_{p m k t} \cdot a_{p} \leq V_{m}, & \forall m, k, t .
\end{array}
$$

Eq. (12) helps determine the quantity of goods loaded on the fleet when exiting DC:

$$
\begin{aligned}
L_{0 p n t}^{\prime}= & \sum_{j} Q W D_{p n j t}^{\prime} \cdot Y W_{n j t}^{\prime} \\
& +\sum_{j} \sum_{\substack{j^{\prime} \\
j \neq j^{\prime}}} Q W D_{p n j j^{\prime} t}^{\prime \prime} \cdot Y W_{n j j^{\prime} t}^{\prime \prime},
\end{aligned}
$$

$\forall p, n, t$.

Constraints (13) and (14) determine the quantity of the load remaining on the fleet after visiting the first buyer related to DC:

$$
\begin{aligned}
L_{p n j t}^{\prime} \geq & L_{0 p n t}^{\prime}-Q W D_{p n j t}^{\prime}+Q W P_{p n j t}^{\prime} \\
& -U \cdot\left(1-Y W_{n j t}^{\prime}\right), \quad \forall p, n, j, t, \\
L_{p n j t}^{\prime} \leq & L_{0 p n t}^{\prime}-Q W D_{p n j t}^{\prime}+Q W P_{p n j t}^{\prime} \\
& +U \cdot\left(1-Y W_{n j t}^{\prime}\right), \quad \forall p, n, j, t .
\end{aligned}
$$

Constraints (15) and (16) are similar to Constraints (13) and (14) with a difference that Constraints (13) and (14) initiate from depots while the former constraints visit other buyers before visiting the new ones:

$$
\begin{aligned}
& L_{p n j t}^{\prime} \geq L_{p n j^{\prime} t}^{\prime}-Q W D_{p n j^{\prime} j t}^{\prime \prime}+Q W P_{p n j^{\prime} j t}^{\prime \prime} \\
& \quad-U \cdot\left(1-Y W_{n j^{\prime} j t}^{\prime \prime}\right), \\
& \forall p, n, j, j^{\prime}\left(j \neq j^{\prime}\right), t, \\
& L_{p n j t}^{\prime} \leq L_{p n j^{\prime} t}^{\prime}-Q W D_{p n j^{\prime} j t}^{\prime \prime}+Q W P_{p n j^{\prime} j t}^{\prime \prime} \\
& \quad+U \cdot\left(1-Y W_{n j^{\prime} j t}^{\prime \prime}\right), \\
& \forall p, n, j, j^{\prime}\left(j \neq j^{\prime}\right), t .
\end{aligned}
$$

Condition of the loaded quantities is determined using Inequality (17): 


$$
L_{p n j t}^{\prime} \leq U \cdot\left(Y W_{n j t}^{\prime}+\sum_{\substack{j^{\prime} \\ j^{\prime} \neq j}} Y W_{n j^{\prime} j t}^{\prime \prime}\right), \quad \forall p, n, j, t .
$$

Constraint (18) calculates the quantity loaded on the fleet when the vehicles leave from the warehouse:

$$
\begin{aligned}
L_{p m t}= & \sum_{k} Q E D_{p m k t}^{\prime} \cdot Y E_{m k t}^{\prime} \\
& +\sum_{k} \sum_{\substack{k^{\prime} \\
k \neq k^{\prime}}} Q E D_{p m k k^{\prime} t}^{\prime \prime} \cdot Y E_{m k k^{\prime} t}^{\prime \prime}
\end{aligned}
$$

$\forall p, m, t$.

Similar to Constraints (13) and (14), Constraints (19) and (20) determine the loaded quantity remaining on fleet after visiting the first buyer:

$$
\begin{aligned}
L_{p m k t} \geq & L_{0 p m t}-Q E D_{p m k t}^{\prime}+Q E P_{p m k t}^{\prime} \\
& -U \cdot\left(1-Y E_{m k t}^{\prime}\right), \quad \forall p, m, k, t, \\
L_{p m k t} \leq & L_{0 p m t}-Q E D_{p m k t}^{\prime}+Q E P_{p m k t}^{\prime} \\
& +U \cdot\left(1-Y E_{m k t}^{\prime}\right), \quad \forall p, m, k, t .
\end{aligned}
$$

Constraints (21) and (22) are similar to Constraints (15) and (16) which compute the quantity being loaded on fleet after visiting the buyers:

$$
\begin{aligned}
& L_{p m k t} \geq L_{p m k^{\prime} t}-Q E D_{p m k^{\prime} k t}^{\prime \prime}+Q E P_{p m k^{\prime} k t}^{\prime \prime} \\
& -U \cdot\left(1-Y E_{m k^{\prime} k t}^{\prime \prime}\right), \quad \forall p, m, k, k^{\prime}\left(k \neq k^{\prime}\right), t, \\
& L_{p m k t} \leq L_{p m k^{\prime} t}-Q E D_{p m k^{\prime} k t}^{\prime \prime}+Q E P_{p m k^{\prime} k t}^{\prime \prime} \\
& \quad+U \cdot\left(1-Y E_{m k^{\prime} k t}^{\prime \prime}\right), \quad \forall p, m, k, k^{\prime}\left(k \neq k^{\prime}\right), t .
\end{aligned}
$$

Similar to Constraint (17), Constraint (23) declares the condition of the loaded quantities for the fleet being responsible for the warehouse:

$$
L_{p m k t} \leq U \cdot\left(Y E_{m k t}^{\prime}+\sum_{\substack{k^{\prime} \\ k^{\prime} \neq k}} Y E_{m k^{\prime} k t}^{\prime \prime}\right),
$$

$\forall p, m, k, t$.

Constraints (24)-(31) elaborate on both sub-tours and routing constraints:

$$
\begin{aligned}
& Y W_{n j t}^{\prime}+\sum_{\substack{j^{\prime} \\
j^{\prime} \neq j}} Y W_{n j^{\prime} j t}^{\prime \prime}=\sum_{\substack{j^{\prime} \\
j^{\prime} \neq j}} Y W_{n j j^{\prime} t}^{\prime \prime}+Z W_{n j t}, \\
& \forall n, j, t,
\end{aligned}
$$

$$
\begin{aligned}
& Y E_{m k t}^{\prime}+\sum_{\substack{k^{\prime} \\
k^{\prime} \neq k}} Y E_{m k^{\prime} k t}^{\prime \prime}=\sum_{\substack{k^{\prime} \\
k^{\prime} \neq k}} Y E_{m k k^{\prime} t}^{\prime \prime}+Z E_{m k t}, \\
& \forall m, k, t, \\
& \sum_{j} Y W_{n j t}^{\prime} \leq 1, \quad \forall n, t, \\
& \sum_{k} Y E_{m k t}^{\prime}+Y_{m t} \leq 1, \quad \forall m, t, \\
& \sum_{\substack{j^{\prime} \\
j^{\prime} \neq j}} Y W_{n j j^{\prime} t}^{\prime \prime}+Z W_{n j t} \leq 1, \quad \forall n, j, t, \\
& \sum_{\substack{k^{\prime} \\
k^{\prime} \neq k}} Y E_{m k k^{\prime} t}^{\prime \prime}+Z E_{m k t} \leq 1, \quad \forall m, k, t, \\
& \sum_{j \neq j^{\prime}} \sum_{j^{\prime}} Y W_{n j j^{\prime} t}^{\prime \prime} \leq U \cdot \sum_{j} Y W_{n j t}^{\prime}, \quad \forall n, t, \quad \\
& \sum_{k \neq k^{\prime}} \sum_{k^{\prime}} Y E_{m k k^{\prime} t}^{\prime \prime} \leq U \cdot \sum_{k} Y E_{m k t}^{\prime}, \quad \forall m, t .
\end{aligned}
$$

Constraints (32)-(35) calculate the amount of inventories in the warehouse and DC in the planning horizon. As presumed in the beginning of the planning horizon, depots have no commodities:

$$
\begin{aligned}
I N V_{p t}^{\prime}= & \sum_{m} Q D_{p m t}+I N V_{p(t-1)}^{\prime}-\sum_{n} \sum_{j} Q W_{p n j t}^{\prime} \\
& -\sum_{n} \sum_{j} \sum_{\substack{j^{\prime} \\
j \neq j^{\prime}}} Q W_{p n j j^{\prime} t}^{\prime \prime}, \quad \forall p, t>\cdot 1,(32) \\
I N V_{p t}^{\prime}= & \sum_{m} Q D_{p m t}-\sum_{n} \sum_{j} Q W D_{p n j t}^{\prime} \\
& -\sum_{n} \sum_{j} \sum_{\substack{j^{\prime} \\
j \neq j^{\prime}}} Q W D_{p n j j^{\prime} t}^{\prime \prime}, \quad \forall p, t=1, \quad(33) \\
I N V_{p t}= & I N V_{p(t-1)}+A P_{p t}-\sum_{m} Q D_{p m t} \\
& -\sum_{m} \sum_{k} Q E D_{p m k t}^{\prime}-\sum_{m} \sum_{k} \sum_{\substack{k^{\prime} \\
k^{\prime} \neq k}} Q E D_{p m k k^{\prime} t}^{\prime \prime},
\end{aligned}
$$

$$
\begin{aligned}
\forall p, t> & 1, \\
I N V_{p t}= & A P_{p t}-\sum_{m} Q D_{p m t}-\sum_{m} \sum_{k} Q E D_{p m k t}^{\prime} \\
& -\sum_{m} \sum_{k} \sum_{\substack{k^{\prime} \\
k^{\prime} \neq k}} Q E D_{p m k k^{\prime} t}^{\prime \prime}, \quad \forall p, t=1 .
\end{aligned}
$$


Constraints (36) and (37) determine the number of lost sales imposed on buyers that have been assigned to the warehouse and DC:

$$
\begin{aligned}
& L S_{p j t}^{\prime}=D_{p j t}^{\prime}-\sum_{n} Q W D_{p n j t}^{\prime}-\sum_{n} \sum_{\substack{j^{\prime} \\
j^{\prime} \neq j}} Q W D_{p n j^{\prime} j t}^{\prime \prime}, \\
& \forall p, j, t, \\
& L S_{p k t}=D_{p k t}-\sum_{m} Q E D_{p m k t}^{\prime}-\sum_{m} \sum_{\substack{k^{\prime} \\
k^{\prime} \neq k}} Q E D_{p m k^{\prime} k t}^{\prime \prime}, \\
& \quad \forall p, k, t .
\end{aligned}
$$

Constraints (38) and (39) calculate lost pickup amounts for each buyer in the planning horizon allocated to DC and the warehouse:

$$
\begin{aligned}
& L P_{p j t}^{\prime}=P_{p j t}^{\prime}-\sum_{n} Q W P_{p n j t}^{\prime}-\sum_{n} \sum_{j^{\prime}} Q W P_{p n j^{\prime} j t}^{\prime \prime}, \\
& \forall p, j, t, \\
& L P_{p k t}=P_{p k t}-\sum_{m} Q E P_{p m k t}^{\prime}-\sum_{m} \sum_{k^{\prime}} Q E P_{p m k^{\prime} k t}^{\prime \prime}, \\
& \forall p, k, t .
\end{aligned}
$$

Constraint (40) shows the maximum level of production quantities a factory can produce:

$$
A P_{p t} \leq \operatorname{cap}_{p t} \cdot W_{p t}, \quad \forall p, t .
$$

Constraints (41) and (42) depict the maximum depot volume for DC and the warehouse:

$$
\begin{array}{ll}
\sum_{p} I n v_{p t}^{\prime} \cdot a_{p} \leq I N V_{\text {max }}^{\prime}, & \forall t, \\
\sum_{p} I n v_{p t} \cdot a_{p} \leq I N V_{\max }, & \forall t .
\end{array}
$$

Eq. (43) calculates the number of products produced by the factory:

$$
\begin{aligned}
& \sum_{t} A P_{p t}=\sum_{n} \sum_{j} \sum_{t} Q W D_{p n j t}^{\prime} \\
& \quad+\sum_{n} \sum_{j} \sum_{\substack{j^{\prime} \\
j \neq j^{\prime}}} \sum_{t} Q W D_{p n j^{\prime} j t}^{\prime \prime}+\sum_{m} \sum_{k} \sum_{t} Q E D_{p m k t}^{\prime} \\
& \quad+\sum_{m} \sum_{k} \sum_{\substack{k^{\prime} \\
k \neq k^{\prime}}} \sum_{t} Q E D_{p m k^{\prime} k t}^{\prime \prime}, \quad \forall p
\end{aligned}
$$

Since the proposed model is nonlinear due to the multiplication of decision variables in Constraints (12) and (18), it is necessary to convert it into a linear coun- terpart. Therefore, the following auxiliary variables $b E_{p m k t}^{\prime}, b E_{p m k k^{\prime} t}^{\prime \prime}, b W_{p n j t}^{\prime}$, and $b W_{p n j j^{\prime} t}^{\prime \prime}$ are defined and Constraints (44)-(51) are added to the main model:

$$
\begin{gathered}
b E_{p m k t}^{\prime}-\left(1-Y E_{m k t}^{\prime}\right) \cdot U \leq Q E D_{p m k t}^{\prime} \leq b E_{p m k t}^{\prime} \\
-\left(1-Y E_{m k t}^{\prime}\right) \cdot U, \quad \forall p, m, k, t, \\
Q E D_{p m k t}^{\prime} \leq U \cdot Y E_{m k t}^{\prime}, \quad \forall p, m, k, t, \\
b E_{p m k k^{\prime} t}^{\prime \prime}-\left(1-Y E_{m k k^{\prime} t}^{\prime \prime}\right) \cdot U \leq Q E D_{p m k k^{\prime} t}^{\prime \prime} \\
\leq b E_{p m k k^{\prime} t}^{\prime \prime}-\left(1-Y E_{m k k^{\prime} t}^{\prime \prime}\right) \cdot U, \\
\forall p, m, k, k^{\prime}\left(k \neq k^{\prime}\right), t, \\
Q E D_{p m k k^{\prime} t}^{\prime \prime} \leq U \cdot Y E_{m k k^{\prime} t}^{\prime \prime}, \quad \forall p, m, k, k^{\prime}\left(k \neq k^{\prime}\right), t, \\
b W_{p n j t}^{\prime}-\left(1-Y W_{n j t}^{\prime}\right) \cdot U \leq Q W D_{p n j t}^{\prime} \leq b W_{p n j t}^{\prime} \\
-\left(1-Y W_{n j t}^{\prime}\right) \cdot U, \quad \forall p, n, j, t, \\
Q W D_{p n j t}^{\prime} \leq U \cdot Y W_{n j t}^{\prime}, \quad \quad \forall p, n, j, t, \\
b W_{p n j j^{\prime} t}^{\prime \prime}-\left(1-Y W_{n j j^{\prime} t}^{\prime \prime}\right) \cdot U \leq Q W D_{p n j j^{\prime} t}^{\prime \prime} \\
\leq b W_{p n j j^{\prime} t}^{\prime \prime}-\left(1-Y W_{n j j^{\prime} t}^{\prime \prime}\right) \cdot U, \\
\forall p, n, j, j^{\prime}\left(j \neq j^{\prime}\right), t, \quad \forall p, n, j, j^{\prime}, t .(51) \\
Q W D_{p n j j^{\prime} t}^{\prime \prime} \leq U \cdot Y W_{n j j^{\prime} t}^{\prime \prime}, \quad \quad \forall, \quad(49)
\end{gathered}
$$

Considering Constraints (44)-(51), Constraints (12) and (18) can be rewritten as follows:

$$
\begin{array}{ll}
L_{0 p n t}^{\prime}=\sum_{j} b W_{p n j t}^{\prime}+\sum_{j} \sum_{\substack{j^{\prime} \\
j \neq j^{\prime}}} b W_{p n j j^{\prime} t}^{\prime \prime}, & \forall p, n, t, \\
L_{0 p m t}=\sum_{k} b E_{p m k t}^{\prime}+\sum_{k} \sum_{\substack{k^{\prime} \\
k \neq k^{\prime}}} b E_{p m k k^{\prime} t}^{\prime \prime}, & \forall p, m, t .
\end{array}
$$

\section{A case study and sensitivity analysis}

This section presents an instance in the form of a case study to validate the proposed model. A newly established factory in the northern region of Iran was considered as a case study. Figure 5 illustrates the location of the related case study. As shown earlier, $D_{1}$ is the location of the factory and its warehouse being responsible for saving and maintaining raw materials and commodities. Besides, this point is the place from which commodities are transferred to DC and some buyers are assigned to the warehouse. In addition, $D_{2}$ is a place that dispatches commodities to the buyers assigned to DC. Moreover, DC receives the picked up goods from those customers. Circle determine the boundary of customers related to each depot. In this 


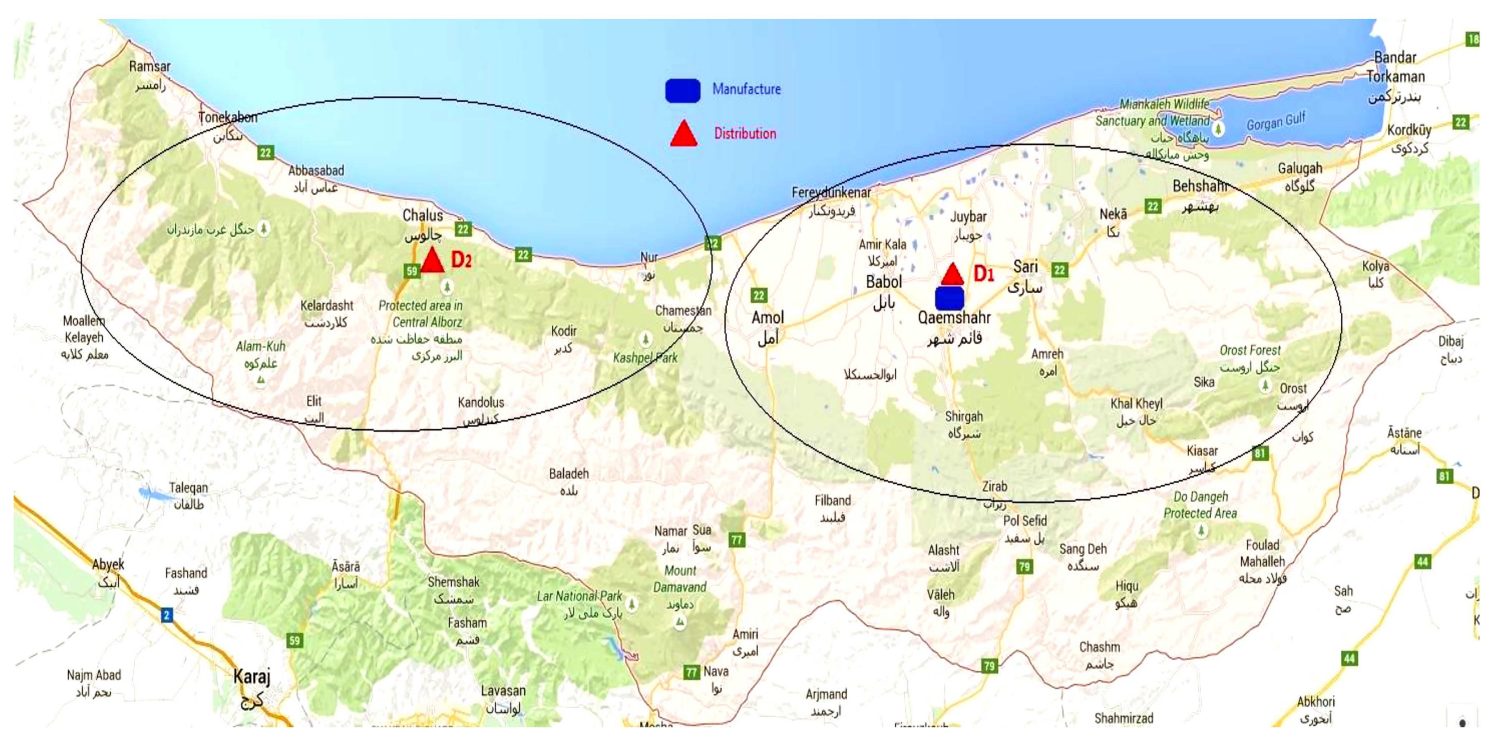

(a)

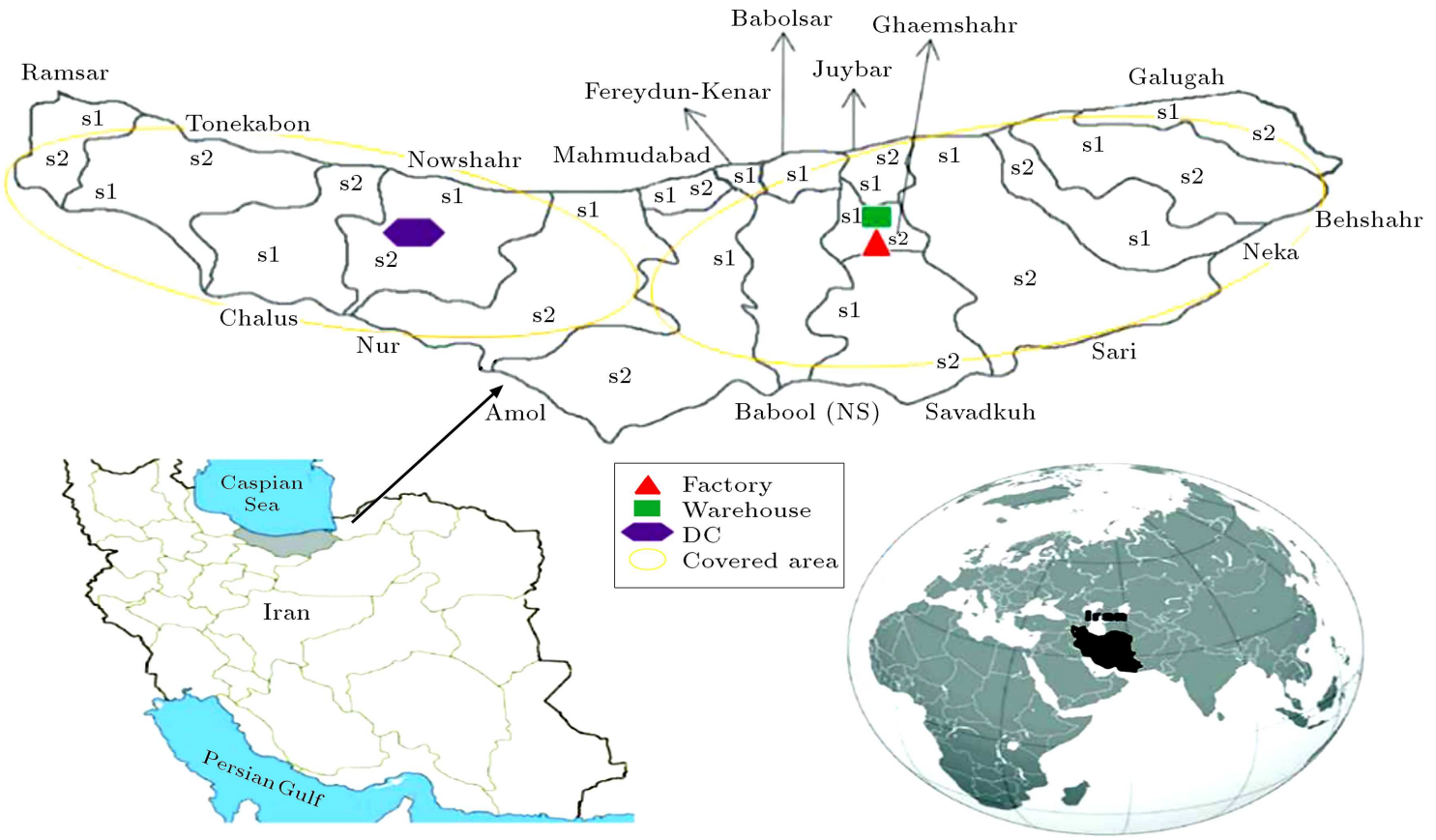

(b)

Figure 5. The span of implementation of the case study.

model, the objective is to convince buyers who purchase in bulk from the factory, large department restaurants, etc. to determine an optimal output for two weeks in the planning horizon.

Model validation is a critically important step in deploying real-world models. To obtain the appropriate result, at first, we design a mathematical model based on some assumptions inspired by a real case and, then, solve it by CPLEX solver to obtain optimal solutions. Then, we examine the results to ensure the higher accuracy of the model.
In fact, to make the solution analysis easier, a small illustrative example as the first trial is extracted from the real case by reducing the problem size. In the first trial, there are only five customers from the east of Mazandaran province with numbers 21 to 25 and five from the west of Mazandaran province with numbers 1 to 5 . For example, the total quantity of pick-ups and deliveries for all buyers in the east and west over two days ( 1 and 11) is presented in Table 1. Three and two homogeneous transporting vehicles with a freight capacity of 30 units are considered for the 
Table 1. The whole quantity of deliveries and pick-ups for the first trial.

\begin{tabular}{|c|c|c|c|}
\hline \multirow{4}{*}{ Frist day } & \multirow{2}{*}{ The whole delivery } & East & 50 \\
\hline & & West & 50 \\
\hline & \multirow{2}{*}{ The whole pick-up } & East & 4 \\
\hline & & West & 4 \\
\hline \multirow{4}{*}{ Eleventh day } & \multirow{2}{*}{ The whole delivery } & East & 50 \\
\hline & & West & 50 \\
\hline & \multirow{2}{*}{ The whole pick-up } & East & 4 \\
\hline & & West & 4 \\
\hline
\end{tabular}

warehouse and DC, respectively. Also, the prices of the first and second commodities are 100 and 2000 monetary units.

Figure 6 details the shipping of the fleet and conveyed deliveries and pick-ups by the fleet. The demand quantity of delivery and pick-up defined by each customer is denoted by signs D (first commodity, second commodity) and $\mathrm{P}$ (first commodity, second commodity) with black color, respectively. Also, the actual number of deliveries and pick-ups transported by a vehicle for a customer is denoted by D (first commodity, second commodity) and $\mathrm{P}$ (first commodity, second commodity) with red and purple colors for the tenth and eleventh days, respectively.

The obtained results of the model solution are given in Figures 6 and 7, depicting a schematic of
Table 2. The outcome of two objective functions for the first trial.
$Z_{1}$

(The whole expenses)
$Z_{2}$

(The whole lost pick-up and lost sales)

\begin{tabular}{cc}
\hline $3,3684 \mathrm{E}+6$ & 20 \\
\hline
\end{tabular}

how to allocate vehicles to transportation, the fleet shipping, and the quantity of deliveries and pick-ups to or from each buyer. Also, the forthcoming table (Table 2) shows the objective function and its value.

According to Figures 6 and 7, the first category of Constraints (3)-(7) as well as that of Constraints (12), (17), (18), and (23) are satisfied so that if the fleet moves from the warehouse to DC or the buyers, it can dispatch or pick up the commodities to or from that DC or the buyers.

The second category of Constraints (8)-(23) does not allow the fleet departing from the warehouse to carry more than its peak volume. Similarly, the amount of load delivered and picked up at the time of meeting the customer should be measured such that after leaving that customer, the loaded quantity on the fleet is less than its peak volume. For instance, when a fleet departs from the warehouse towards buyer 21 on the first day, it has loaded 30 quantities being equal to its peak volume and delivered 10 quantities to the range of customers 21 to 23 . When it meets customer 21 , it delivers 5 quantities of the first commodity and

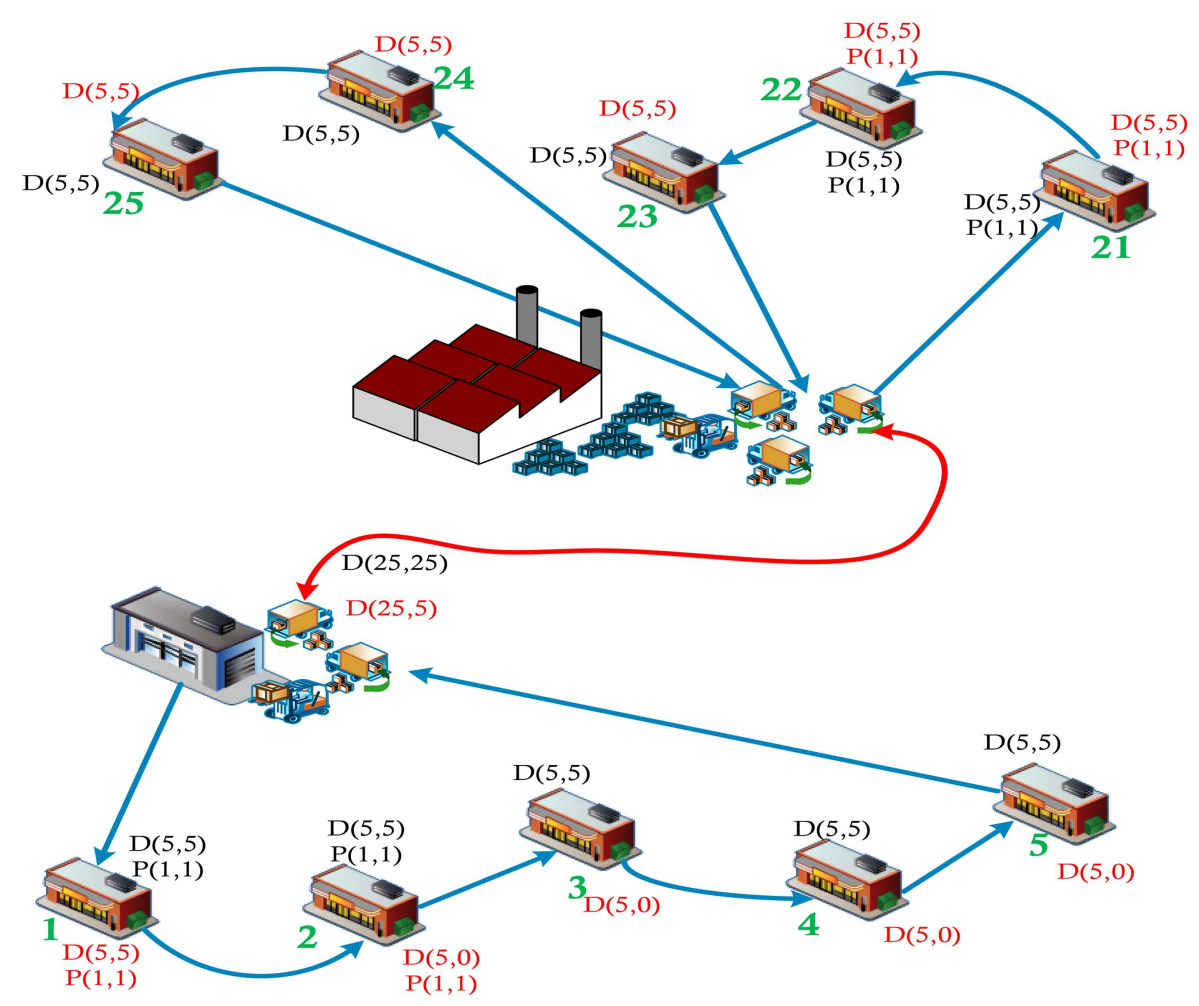

Figure 6. The graphic solution on the first day for the first trial. 


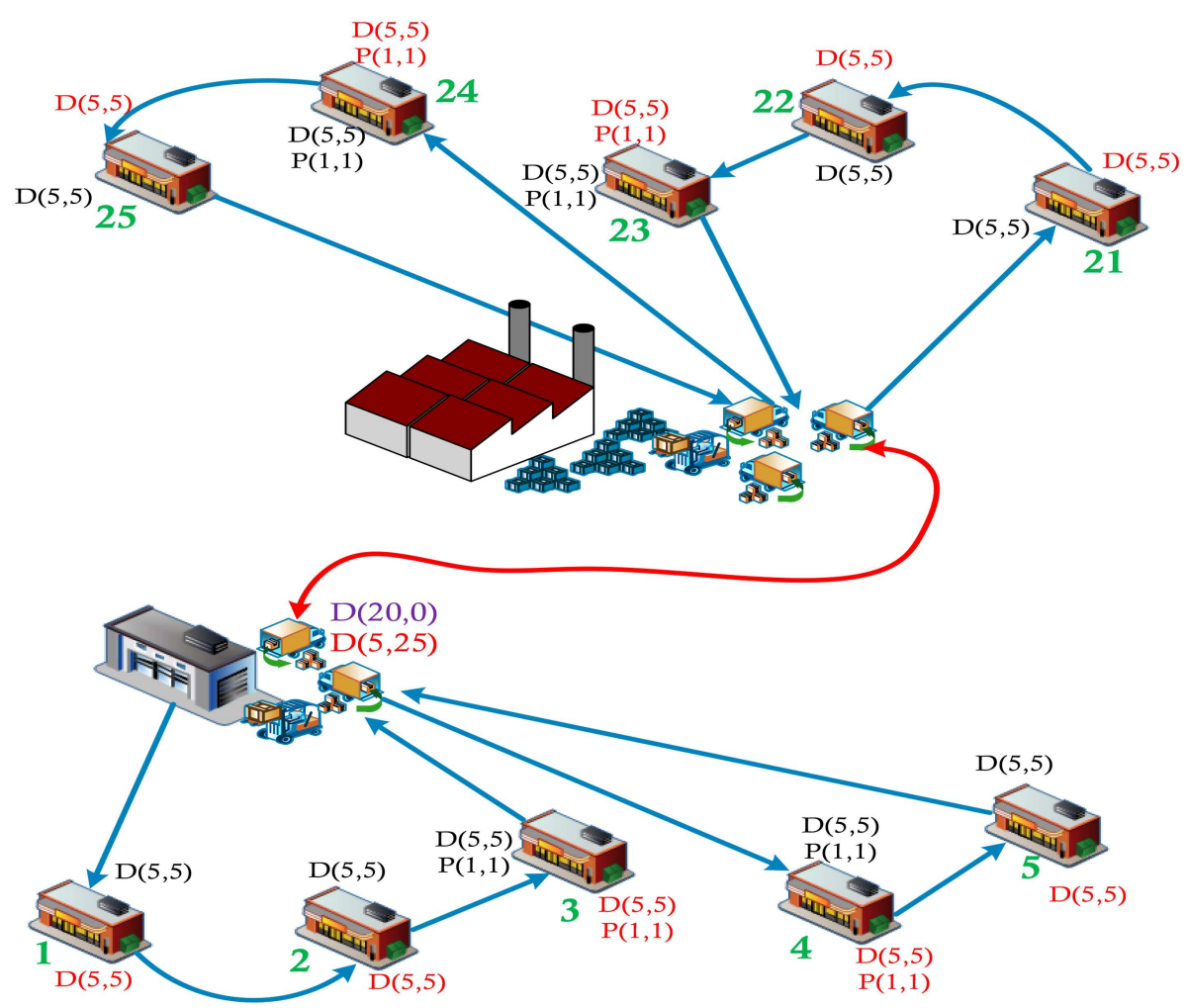

Figure 7. The graphic solution on the tenth and eleventh days for the first trial.

5 quantities of the second commodity. Afterward, it picks up 1 quantity of each commodity as an item to be picked up and returned to the factory. The fleet is transferring 22 quantities of commodities departing from buyer 21, being less than its volume. Another category of Constraints (24)-(31) as shipping ones works to prevent sub-tours from taking any action.

On the start day, we encounter a shortage of 20 units of type- 2 products demanded by customers 2 , 3,4 , and 5 allocated to the warehouse; however, on the eleventh day, the entire requests are satisfied. The reason is that on the first day, there were 50 demands from the customers assigned to DC and there was only one vehicle having the volume of 30 quantities for delivering the commodities from the factory to DC. As a result, there was a shortage of 20 product units.

Now, two important questions arise: first of all, 'Why does the solution provide commodities for more buyers like the fourth and fifth buyers rather than satisfy the requests of the nearby buyers (e.g., the second commodity for the second and third buyers)?' Does it occur frequently for transportation cost in the objective function? Equally important, if there were more fleets moving from the factory to DC, would the buyers allocated to the warehouse run into any commodity shortage?

The response to the first question is that due to the variable production costs expressed in the objective function and considering the fact that the variable production costs for the first and second products are 100 and 2000 units, respectively, the model helps conclude that the production costs outweigh transportation costs for the second product according to the constraints of fleet volume on the first day. In addition, based on a comparison made between the floating shipping expenses and the manufacturing ones as well as considering the second objective function aimed at minimizing the lost sales, costs are quite lower in this situation. Therefore, it is more affordable and less expensive to produce product 1 .

To validate this assertion and to ensure the accurate performance of the model, it is supposed that the values of the second and first commodities are the same (2000 units) and the first trial is solved again. The results were subject to variation only on the first day, as shown in Figure 8.

As shown in Figure 8, by considering the prices of two commodities equal and according to the expenses in the objective function, the mathematical model helps decide to give no services to customers 4 and 5 instead of meeting all demands of buyers 2 and 3 . When the costs of production and inventory holding are equal for both products, service is considered for the nearby buyers based on transportation costs.

In response to the second question, due to volume constraints and number of shipping fleets of the warehouse in the first trial, we have encountered product shortage for the customer assigned to DC. 


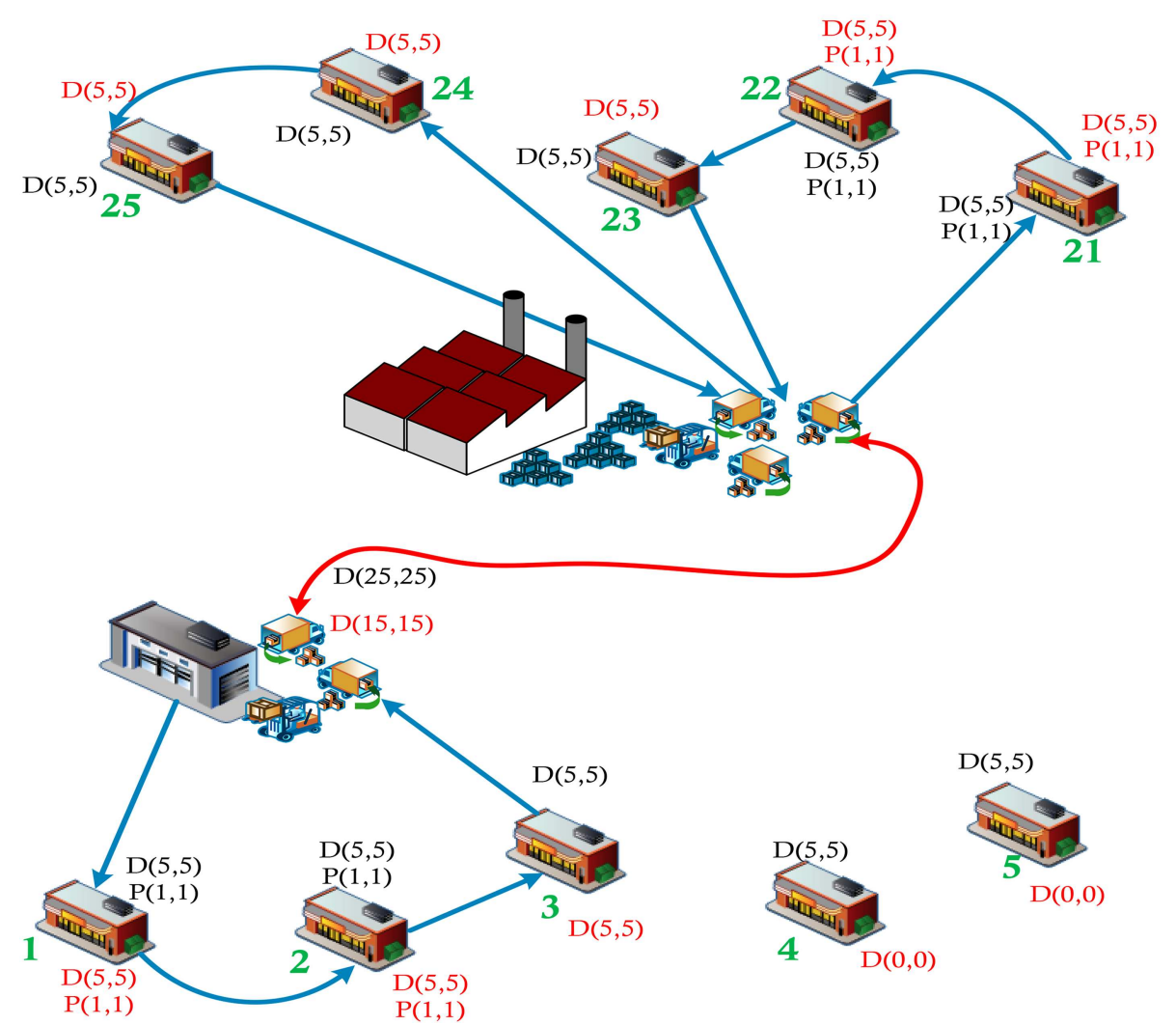

Figure 8. The graphic solution after a change in the value of the first commodity on the first day.

Table 3. The second trial data.

\begin{tabular}{cl}
\hline First day & $\begin{array}{l}\text { All delivery requests of buyers are } 100 \text { units } \\
\text { All pick-up requests to buyers are } 8 \text { units }\end{array}$ \\
Eleventh day & $\begin{array}{l}\text { All delivery requests of buyers are } 100 \text { units } \\
\text { All pick-up requests to buyers are } 8 \text { units }\end{array}$ \\
Warehouse & $\begin{array}{c}\text { Four homogeneous shipping fleets } \\
\text { (The tonnage of each vehicle is } 30 \text { units) }\end{array}$ \\
DC & $\begin{array}{c}\text { Two homogeneous shipping fleets } \\
\text { (The tonnage of each vehicle is } 30 \text { units) }\end{array}$ \\
Value of the first commodity, 100 units & Value of the second commodity, 2000 units \\
\hline
\end{tabular}

In the second trial, an increase in the number of fleets assigned to the warehouse from three to four verifies the model accuracy. Therefore, it is expected that with this growth, we do not face any shortage. Table 3 shows the second trial with its parameters.

Figure 9 and Table 4 show the acquired outcomes for the second trial.

The warehouse has four vehicles named $a$ to $d$. Vehicles $a$ and $b$ offer services to the buyers who are allocated to the factory, and $c$ and $d$ carry products to DC. As be seen in Figure 9, by adding vehicle $d$, there is not any product shortage on the first day.
Table 4. The outcome of two objective functions for the second trial.

\begin{tabular}{cc}
\hline $\begin{array}{c}Z_{1} \\
\text { (The whole expenses) }\end{array}$ & $\begin{array}{c}Z_{2} \\
\text { (All lost pick-ups } \\
\text { and lost sales) }\end{array}$ \\
\hline $3,7787 \mathrm{E}+6$ & 0 \\
\hline
\end{tabular}

After confirming the viability of the model in solving a small-sized problem, a real case problem with a larger dimension is solved to validate the model and the results in the following section are reported. 


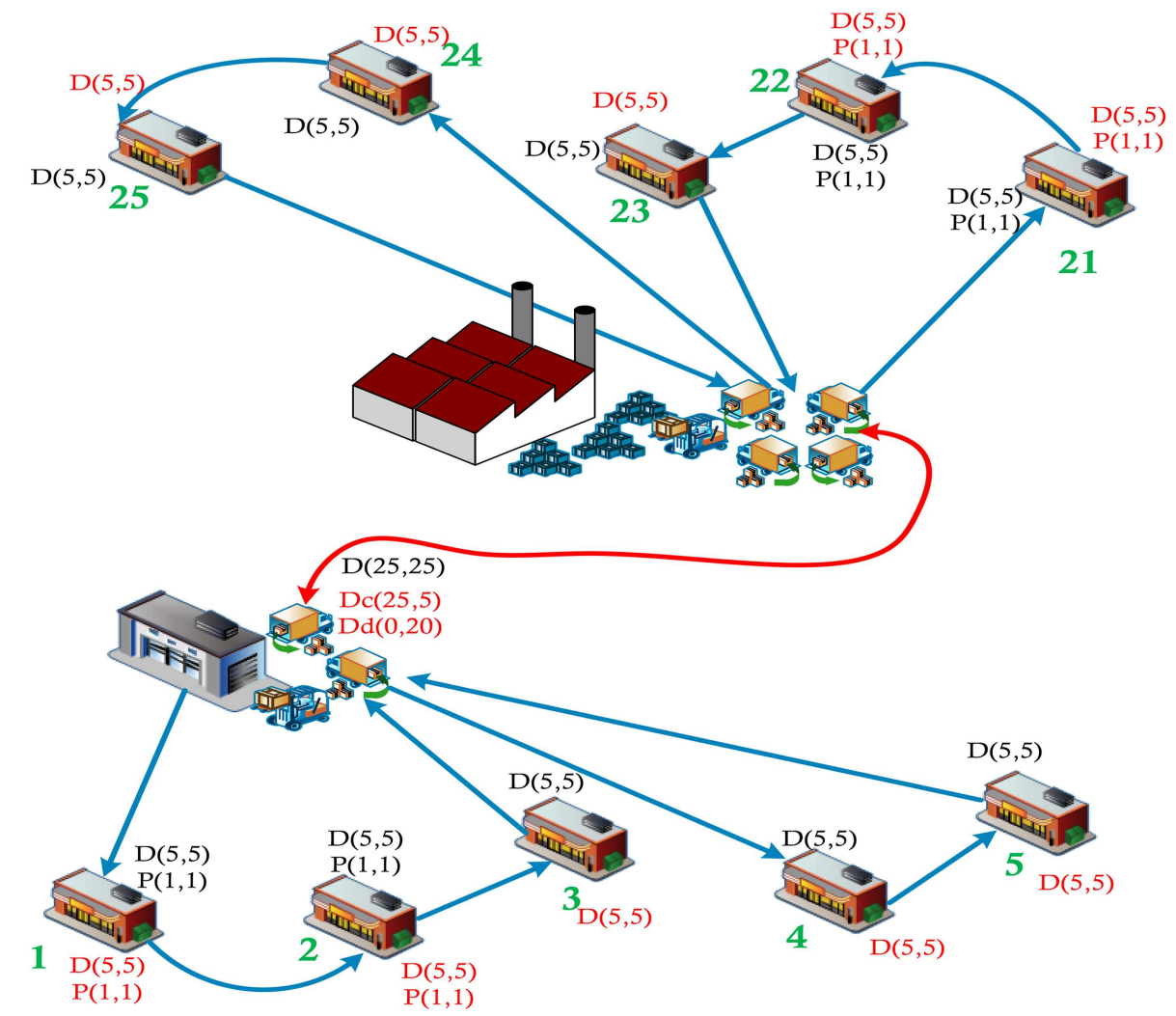

Figure 9. The graphic solution on the first day for the second trial.

Table 5. Distances between the customers.

\begin{tabular}{cccccccccccccccc}
\hline & \multicolumn{10}{c}{} & \multicolumn{10}{c}{ Buyers } & $\mathbf{1}$ & $\mathbf{2}$ & $\mathbf{3}$ & $\mathbf{4}$ & $\mathbf{5}$ & $\mathbf{6}$ & $\mathbf{7}$ & $\mathbf{8}$ & $\mathbf{9}$ & $\mathbf{1 0}$ & $\mathbf{1 1}$ & $\mathbf{1 2}$ & $\mathbf{1 3}$ & $\mathbf{1 4}$ & $\mathbf{1 5}$ \\
\hline $\mathbf{1}$ & 0 & 0 & 2.93 & 2.88 & 1.7 & 1.75 & 2.26 & 2.27 & 2.28 & 2.29 & 3.09 & 4.95 & 4.9 & 7.95 & 6.29 \\
$\mathbf{2}$ & 0 & 0 & 2.93 & 2.88 & 1.7 & 1.75 & 2.26 & 2.27 & 2.28 & 2.29 & 3.09 & 4.95 & 4.9 & 7.95 & 6.29 \\
$\mathbf{3}$ & 2.93 & 2.93 & 0 & 0.05 & 2.08 & 2.13 & 2.25 & 2.26 & 2.27 & 2.28 & 3.05 & 3.88 & 3.93 & 8.43 & 7.02 \\
$\mathbf{4}$ & 2.88 & 2.88 & 0.05 & 0 & 2.13 & 2.18 & 2.3 & 2.31 & 2.32 & 2.33 & 3.1 & 3.93 & 3.98 & 8.48 & 7.07 \\
$\mathbf{5}$ & 1.7 & 1.7 & 2.08 & 2.13 & 0 & 0.05 & 0.56 & 0.57 & 0.58 & 0.59 & 1.44 & 1.8 & 1.85 & 6.25 & 4.84 \\
$\mathbf{6}$ & 1.75 & 1.75 & 2.13 & 2.18 & 0.05 & 0 & 0.61 & 0.62 & 0.63 & 0.64 & 1.39 & 1.75 & 1.8 & 6.2 & 4.8 \\
$\mathbf{7}$ & 3.09 & 3.09 & 2.25 & 2.3 & 1.39 & 1.34 & 0 & 0.01 & 0.02 & 0.03 & 0.86 & 2.38 & 2.43 & 6.83 & 5.38 \\
$\mathbf{8}$ & 3.1 & 3.1 & 2.26 & 2.31 & 1.38 & 1.33 & 0.01 & 0 & 0.01 & 0.02 & 0.85 & 2.37 & 2.42 & 6.82 & 5.37 \\
$\mathbf{9}$ & 3.11 & 3.11 & 2.27 & 2.32 & 1.37 & 1.32 & 0.02 & 0.01 & 0 & 0.01 & 0.84 & 2.36 & 2.41 & 6.81 & 5.36 \\
$\mathbf{1 0}$ & 3.12 & 3.12 & 2.28 & 2.33 & 1.36 & 1.31 & 0.03 & 0.02 & 0.01 & 0 & 0.83 & 2.35 & 2.4 & 6.8 & 5.35 \\
$\mathbf{1 1}$ & 3.92 & 3.92 & 3.05 & 3.1 & 2.27 & 2.22 & 0.86 & 0.85 & 0.84 & 0.83 & 0 & 1.93 & 1.98 & 6.43 & 4.98 \\
$\mathbf{1 2}$ & 4.95 & 4.95 & 3.88 & 3.93 & 1.8 & 1.75 & 2.38 & 2.37 & 2.36 & 2.35 & 1.93 & 0 & 0.05 & 4.5 & 3.05 \\
$\mathbf{1 3}$ & 4.9 & 4.9 & 3.93 & 3.98 & 1.85 & 1.8 & 2.43 & 2.42 & 2.41 & 2.4 & 1.98 & 0.05 & 0 & 4.45 & 3 \\
$\mathbf{1 4}$ & 7.95 & 7.95 & 8.43 & 8.48 & 6.25 & 6.2 & 6.83 & 6.82 & 6.81 & 6.8 & 6.43 & 4.5 & 4.45 & 0 & 3.18 \\
$\mathbf{1 5}$ & 6.29 & 6.29 & 7.02 & 7.07 & 4.84 & 4.8 & 5.38 & 5.37 & 5.36 & 5.35 & 4.98 & 3.05 & 3 & 3.18 & 0 \\
\hline
\end{tabular}

In this case study, there are 15 buyers thatare allocated to DC and 15 buyers allocated to the warehouse who are orderly named from 1 to 34 . There are 3 types of commodities demanded by customers. The buyers demand the commodity delivery and pickup requests to be satisfied all together on the first, second, third, fourth, fifth, eighth, tenth, twelfth, and thirteenth days of the planning horizon. In addition,
900 and 61 commodities upon the delivery request and pick-up are considered, respectively, in this case study along with four and three fleets in the warehouse and DC, respectively. The fleets are homogeneous whose capacities are 30 units in volume. The proposed mathematical model is solved using CPLEX program.

Tables 5-7 include all the parameters considered to present a case study. Table 5 represents the space 
Table 6. The distance between the factory and the buyers allocated to the warehouse.

\begin{tabular}{lccccccccccccccc}
\hline Buyers & $\boldsymbol{B}_{\mathbf{1}}$ & $\boldsymbol{B}_{\mathbf{2}}$ & $\boldsymbol{B}_{\mathbf{3}}$ & $\boldsymbol{B}_{\mathbf{4}}$ & $\boldsymbol{B}_{\mathbf{5}}$ & $\boldsymbol{B}_{\mathbf{6}}$ & $\boldsymbol{B}_{\mathbf{7}}$ & $\boldsymbol{B}_{\mathbf{8}}$ & $\boldsymbol{B}_{\mathbf{9}}$ & $\boldsymbol{B}_{\mathbf{1 0}}$ & $\boldsymbol{B}_{\mathbf{1 1}}$ & $\boldsymbol{B}_{\mathbf{1 2}}$ & $\boldsymbol{B}_{\mathbf{1 3}}$ & $\boldsymbol{B}_{\mathbf{1 4}}$ & $\boldsymbol{B}_{\mathbf{1 5}}$ \\
\hline Factory & 1.84 & 1.84 & 4.64 & 4.59 & 3.51 & 3.56 & 4.12 & 4.13 & 4.14 & 4.15 & 4.91 & 6.76 & 6.71 & 10.82 & 8.3 \\
\hline
\end{tabular}

Table 7. The amount of demands for each buyer.

\begin{tabular}{|c|c|c|c|c|c|c|c|c|c|c|c|c|c|c|c|c|}
\hline & \multirow[b]{2}{*}{ Commodity } & \multicolumn{15}{|c|}{ Buyers } \\
\hline & & $B_{1}$ & $\boldsymbol{B}_{2}$ & $\boldsymbol{B}_{\mathbf{3}}$ & $B_{4}$ & $B_{5}$ & $B_{6}$ & $B_{7}$ & $B_{8}$ & $\boldsymbol{B}_{9}$ & $B_{10}$ & $B_{11}$ & $B_{12}$ & $B_{13}$ & $B_{14}$ & $B_{15}$ \\
\hline Delivery & 1 & 3 & 2 & 3 & 4 & 3 & 4 & 5 & 4 & 5 & 3 & 2 & 3 & 4 & 5 & 2 \\
\hline Demand & 2 & 2 & 3 & 4 & 3 & 2 & 3 & 3 & 2 & 2 & 3 & 2 & 2 & 3 & 4 & 2 \\
\hline Pick-up & 1 & & & & 1 & & & & & & & 1 & & & & \\
\hline Demand & 2 & & 1 & & & & 1 & & & & & & 1 & & & \\
\hline
\end{tabular}

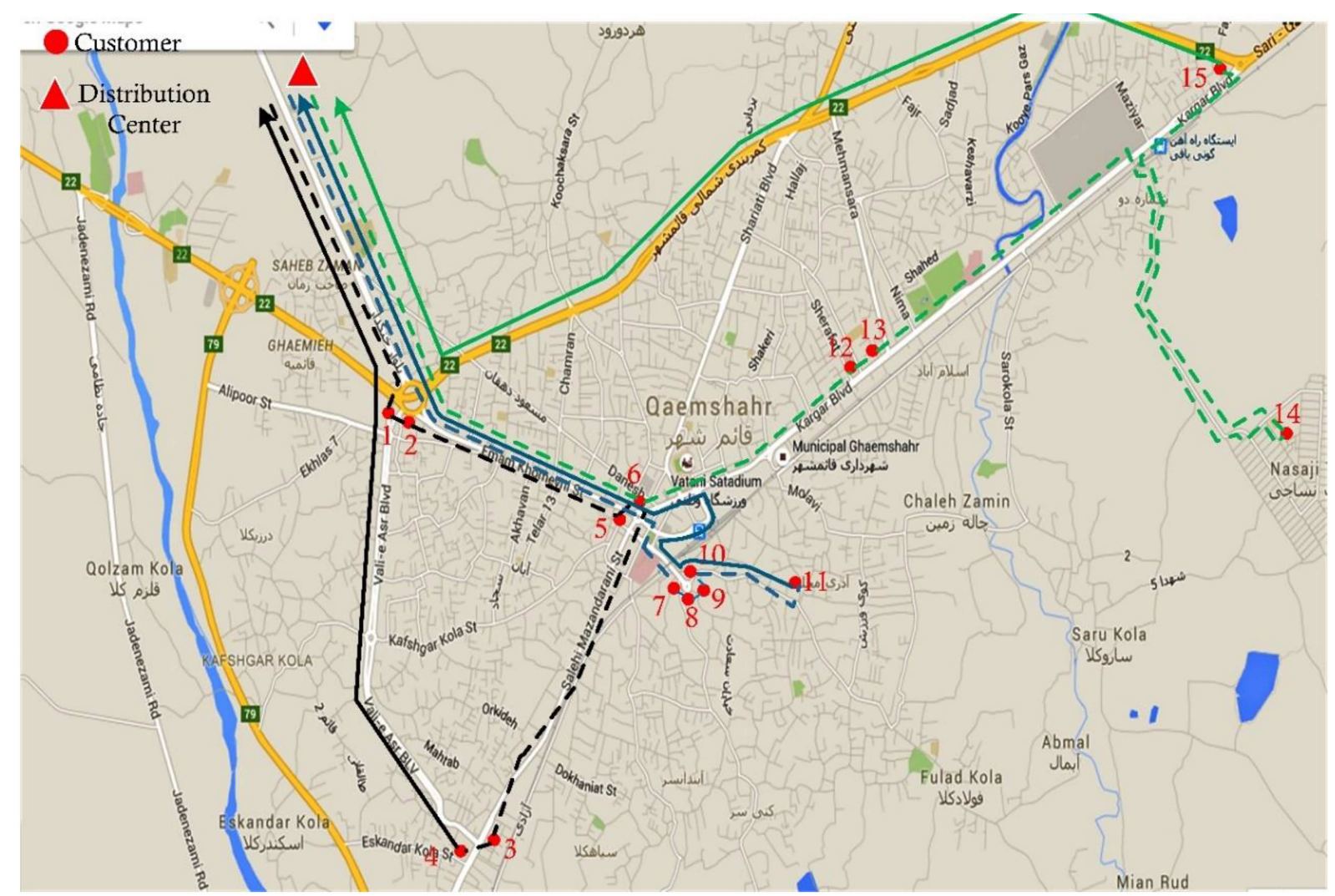

Figure 10. The fleet shipping in Qaemshahr on the second day.

among the buyers. Table 6 shows the space among the factory and buyers. Table 7 depicts the amount of demand by each buyer on the second day. It is worth mentioning that all packs of the first and second products include 250 and 24 units with the same volume, respectively.

Next, the routes traveled by the transportation vehicles on the second day of the planning horizon in a city north of Iran (Qaemshahr) are depicted in Figure 10 .

The paths of transportation vehicles are depicted in Figure 10. The doted path illustrates the travel from the warehouse to the customers, and the solid line depicts the travel of transportation fleet when it leaves the last customer and returns to the warehouse. Table 8 elaborates on the fleet movement.

In Table 8 , the buyers whose requests have not been totally satisfied by the corresponding fleet belong to the deficiency (shortage) column for buyers. Moreover, when buyers' demands are met by more than one fleet, the buyer belongs to the column of the shared buyers. For instance, as shown in Table 8, fleets $C$ 
Table 8. The detail of fleet shipping in Qaemshahr, Iran on the second day.

\begin{tabular}{cccccc}
\hline Vehicle & Color of route & Met buyers & $\begin{array}{c}\text { The deficiency } \\
\text { of any path }\end{array}$ & $\begin{array}{c}\text { Deficient } \\
\text { buyers }\end{array}$ & Shared buyers \\
\hline C & Black & $1,2,5,6,3,4$ & 0 & - & 6 \\
D & Blue & $7,8,9,10,11$ & 1 & 11 & - \\
E & Green & $6,12,13,14,15$ & 1 & 15 & 6 \\
\hline
\end{tabular}

Table 9. The obtained results with different scenarios for Split Delivery Vehicle Routing Problem (SDVRP) and Vehicle Routing Problem (VRP) states.

\begin{tabular}{ccccccc}
\hline & Scenario & Demand & Lost sales & $\begin{array}{c}\text { The number of } \\
\text { delivered products }\end{array}$ & Total cost & $\begin{array}{c}\text { The cost per } \\
\text { delivered product }\end{array}$ \\
\hline \multirow{3}{*}{ SDVRP } & 1 & 72 & 0 & 72 & 4947400 & 68714 \\
& 2 & 81 & 0 & 81 & 5238500 & 64673 \\
& 3 & 90 & 0 & 90 & 5533900 & 61488 \\
& 4 & 99 & 9 & 90 & 5530000 & 61444 \\
VRP & 108 & 18 & 90 & 5529200 & 61436 \\
& 1 & & & & & 68714 \\
& 2 & 81 & 4 & 72 & 4947400 & 66447 \\
& 3 & 90 & 12 & 77 & 5116400 & 65901 \\
& 4 & 99 & 19 & 80 & 5140300 & 65068 \\
\hline
\end{tabular}

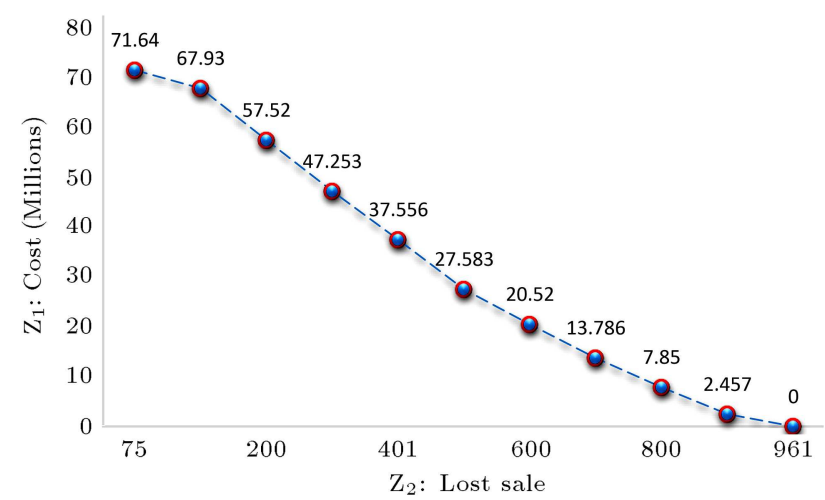

Figure 11. Pareto front for case study.

and $E$ are responsible for meeting the sixth buyer. Figure 11 illustrates the obtained Pareto graph.

As mentioned in the introduction, the mean of shipping expenses in Iran is between 1.7 and 2 times that of the international average based on the report from the Iran Chamber of Commerce Industries, Mines, and Agriculture and the World Bank. Transportation, inventory, and management costs on which this paper focuses are related to the logistic cost. For managers to gain better efficiency in managing the routing planning for the daily operations in the entire supply chain, they can count on the developed model given its viability and practicality for decision-makers in making operational and tactical decisions. In addition, the outcome of Pareto solution helps managers make better choices in different situations and ensure a trade-off between costs and lost sales in various conditions.
In this section, the effect of split delivery on the model performance is evaluated through the addition of Constraints (54) and (55) and it is the reason why each customer is visited at most once by only a vehicle on any one day of planning horizon and, also, split delivery feature is omitted.

For more simplicity, only the demand for the products on one day of planning horizon is considered.

$$
\begin{array}{ll}
\sum_{k} Y E_{m k t}^{\prime}+\sum_{m} \sum_{\substack{k^{\prime} \\
k^{\prime} \neq k}} Y E_{m k^{\prime} k t}^{\prime \prime} \leq 1, \quad & \forall k, t, \\
\sum_{j} Y W_{n j t}^{\prime}+\sum_{n} \sum_{\substack{j^{\prime} \\
j^{\prime} \neq j}} Y W_{n j^{\prime} j t}^{\prime \prime} \leq 1, \quad \forall j, t .
\end{array}
$$

Now, we compare the model performance in two VRP and SDVRP states with five different scenarios. In the third scenario, the whole quantity of deliveries to the customers is exactly matching the total capacity of vehicles. In the first, second, fourth, and fifth scenarios, the demands are considered as $0.8,0.9,1.1$, and 1.2 of total vehicles' capacity, respectively. The fleet's capacity in all scenarios is 90 units.

The results obtained with different scenarios for SDVRP and VRP represented in Table 9 are depicted by Figures $12-17$.

According to Figure 12 and as is predictable in advance, the scarcity value of demand for products delivery increases in the VRP state compared to SD- 


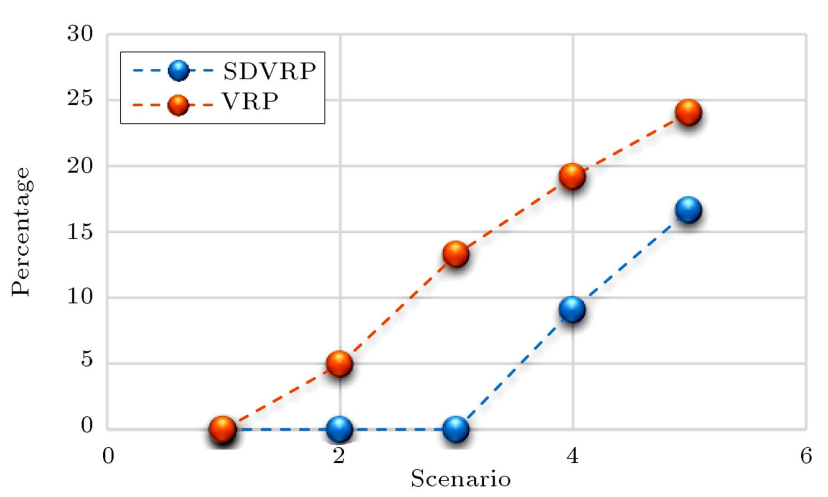

Figure 12. The number of lost sales for five scenarios.

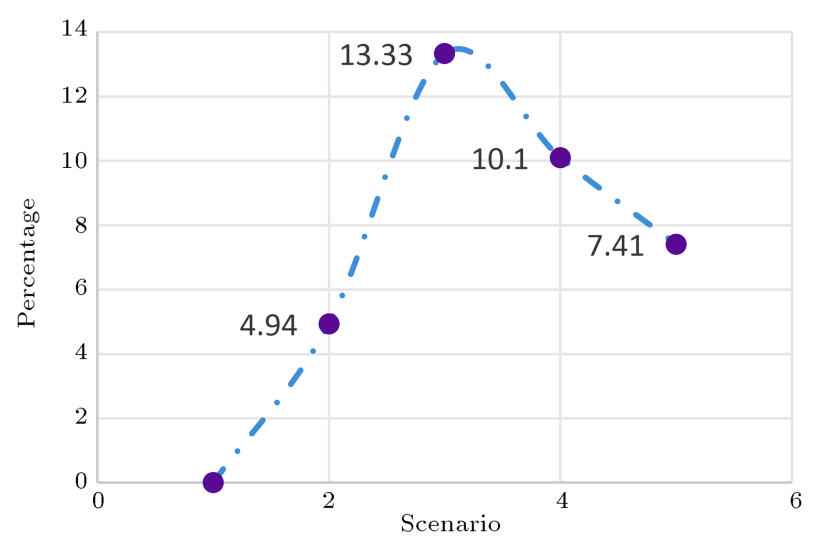

Figure 13. The relative gap of load shortage delivered to customers between Vehicle Routing Problem (VRP) and Split Delivery Vehicle Routing Problem (SDVRP) states for five scenarios.

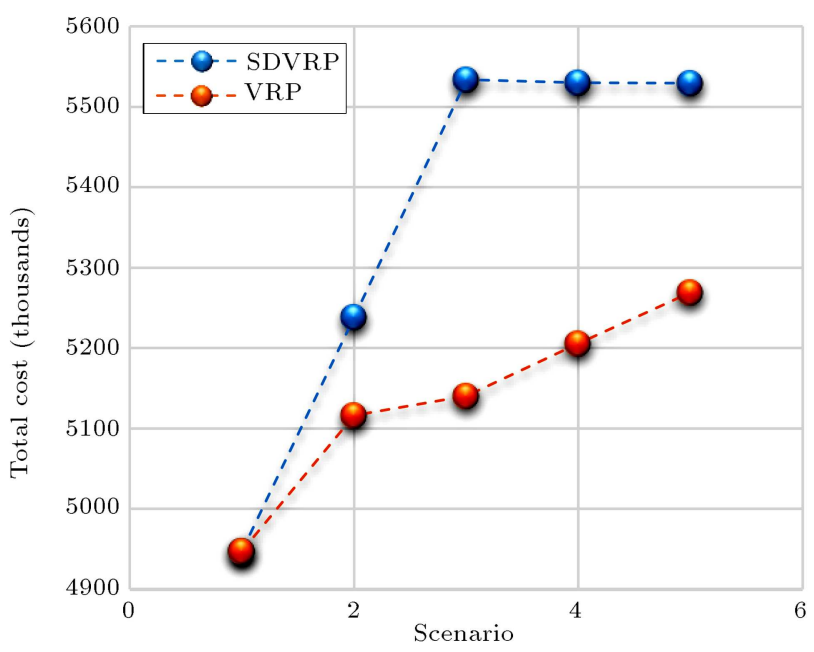

Figure 14. Total costs for five scenarios.

VRP. The relative gap of product shortages in VRP and SDVRP states is shown in Figure 13.

In the third scenario where customers' demand is matching the peak volume of the fleet, the widest gap occurs

Total costs of VRP and SDVRP states for the five scenarios are presented in Figure 14. This figure shows

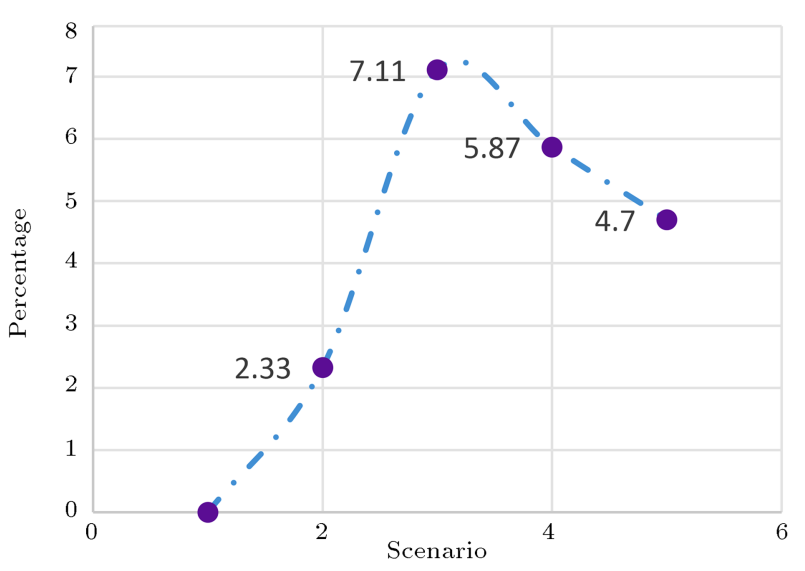

Figure 15. The relative gap of total costs between Vehicle Routing Problem (VRP) and Split Delivery Vehicle Routing Problem (SDVRP) states for five scenarios.

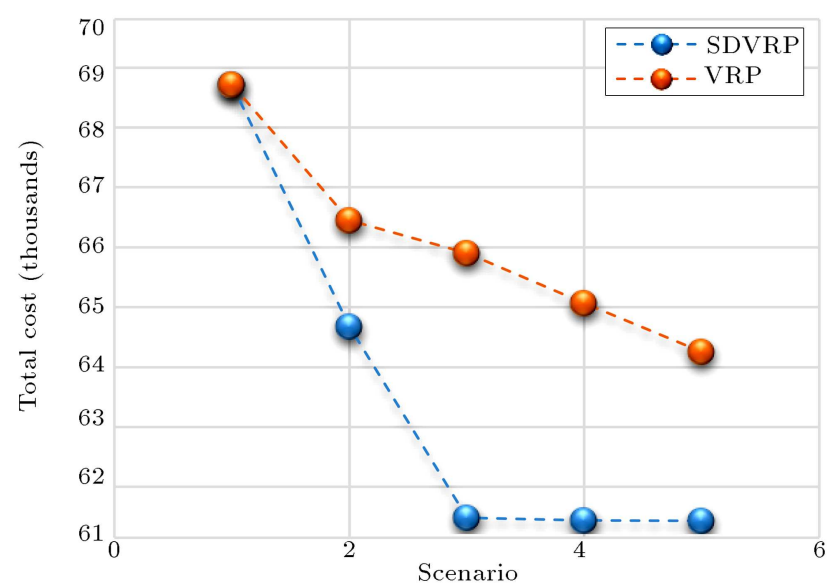

Figure 16. Unit cost per delivered products for each scenario.

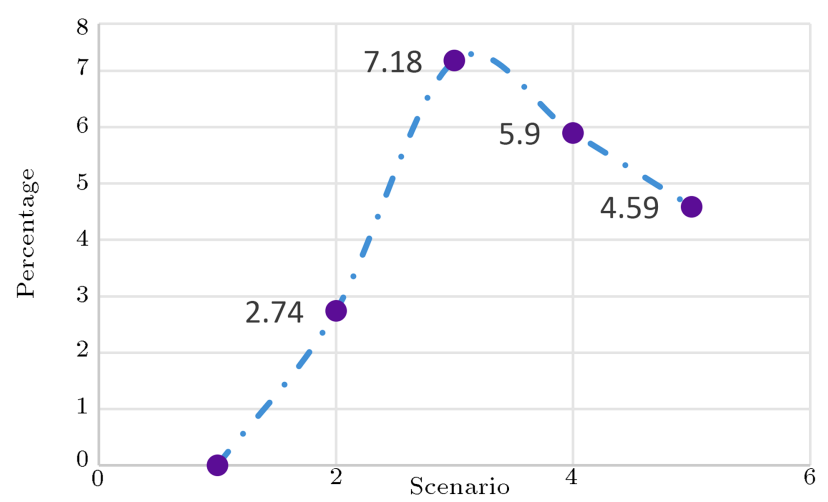

Figure 17. The relative gap of unit costs per products delivered to customers between Vehicle Routing Problem (VRP) and Split Delivery Vehicle Routing Problem (SDVRP) states.

that in the SDVRP state, due to the higher effective utilization of transportation vehicles and higher production level for better services to the customers which result in decreasing the amount of lost sales, the supply 
chain costs increase. The relative gap of costs for each scenario are given in Figure 15.

In Figure 16, the unit cost per delivered product is shown by splitting the whole costs of supply chain into the quantity of products delivered to the customers. In the third scenario, the total cost in the SDVRP state is about $7 \%$ more than VRP one, whereas, according to Figure 17, the unit cost of products delivered to customers in the SDVRP state is $7 \%$ less than VRP one. Final results reveal that SDVRP produces greater demand satisfaction with a lower cost per delivered products.

\section{Conclusions}

The main goal of the current study was to determine the model focusing on the supply chain network issues by utilizing the mixed-integer programming approach. The objectives were to minimize both the whole expenses consisting of transportation, production, and inventory as well as the lost sales. An $\varepsilon$-constraint approach was used to work out the mathematical model by GAMS software. Then, the model was analyzed to ensure the model validation. A real case in an Iranian food industry was considered to verify the results and present the vehicle routings in a day.

Another purpose of this research was to investigate the performance of the considered supply chain and its productivity. In the small-sized instances, by changing the parameters, five scenarios were designed to compare the performance of the model in both Vehicle Routing Problem (VRP) and SDVRP states. As a result, in all scenarios, in case of SDVRP, lost sale was reduced, while by using just traditional VRP, total cost was reduced. Besides, the results demonstrated that the unit cost per delivered product for each scenario in SDVRP was lower than or equal to VRP. The outcomes of the case study confirmed the superior efficiency of employing the SDVRP to the VRP. Indeed, the cost of products delivered to customers in the SDVRP state was $7 \%$ lower than that in the VRP one. The outcomes showed that when managers seek to gain better efficiency in managing routing planning for daily operations in the entire supply chain, they can count on the developed model for this model which could be extended to decision-makers in making operational and tactical decisions.

For future studies, comprehensive analyses should be carried out using some techniques on large scales such as metaheuristic algorithms. In this regard, the mentioned model for common purposes like fresh fruits, food, etc. can be one of the research spaces for future studies. Besides, some real constraints can be employed to extend the mathematical model such as stochastic models with uncertain parameters, crossdock scheduling, etc.

\section{References}

1. Fard, A.M.F. and Hajiaghaei-Keshteli, M. "A tri-level location-allocation model for forward/reverse supply chain", Applied Soft Computing, 62, pp. 328-346 (2018).

2. Shi, Y., Boudouh, T., and Grunder, O. "An efficient tabu search based procedure for simultaneous delivery and pick-up problem with time window", IFACPapers OnLine, 51(11), pp. 241-24 (2018).

3. Soleimani Sedehi, M. "The part of logistics costs from the cost of goods in Iran", Scientific Monthly Newsletter of Logistics \& Supply Chain, 1(7) (Sept., 2011).

4. Ahkamiraad, A. and Wang, Y. "Capacitated and multiple cross-docked vehicle routing problem with pickup, delivery, and time windows", Computers \& Industrial Engineering, 119, pp. 76-84 (2018).

5. Haddad, M.N., Martinelli, R., Vidal, T., Martins, S., Ochi, L.S., Souza, M.J.F., and Hartl, R. "Large neighborhood-based metaheuristic and branch-andprice for the pickup and delivery problem with split loads", European Journal of Operational Research, 270(3), pp. 1014-1027 (2018).

6. Hajiaghaei-Keshteli, M. and Sajadifar, S.M. "Deriving the cost function for a class of three-echelon inventory system with N-retailers and one-for-one ordering policy", The International Journal of Advanced Manufacturing Technology, 50(1-4), pp. 343-351 (2010).

7. Seyedhosseini, S.M. and Ghoreyshi, S.M. "An integrated model for production and distribution planning of perishable products with inventory and routing considerations", Mathematical Problems in Engineering (2014).

8. Miranda, P.L., Morabito, R., and Ferreira, D. "Optimization model for a production, inventory, distribution and routing problem in small furniture companies", TOP, 26(1), pp. 30-67 (2018).

9. Hajiaghaei-Keshteli, M., Sajadifar, S.M., and Haji, R. "Determination of the economical policy of a threeechelon inventory system with $(\mathrm{R}, \mathrm{Q})$ ordering policy and information sharing", The International Journal of Advanced Manufacturing Technology, 55(5-8), pp. 831-841 (2011).

10. Golshahi-Roudbaneh, A., Hajiaghaei-Keshteli, M., and Paydar, M.M. "A hybrid approach in metaheuristics for a cross-dock scheduling considering time windows and deadline for trucks departure", Scientia Iranica, 28(1), pp. 532-546 (2019).

11. Liu, S. and Papageorgiou, L.G. "Multiobjective optimisation of production, distribution and capacity planning of global supply chains in the process industry", Omega, 41(2), pp. 369-382 (2013).

12. Dantzig, G.B. and Ramser, J.H. "The truck dispatching problem", Management Science, 6(1), pp. 80-91 (1959). 
13. Polimeni, A. and Vitetta, A. "Optimising waiting at nodes in time-dependent networks: cost functions and applications", Journal of Optimization Theory and Applications, 156(3), pp. 805-818 (2013).

14. Ozsoydan, F.B. and Sipahioglu, A. "Heuristic solution approaches for the cumulative capacitated vehicle routing problem", Optimization, 62(10), pp. 13211340 (2013).

15. Bertazzi, L. and Speranza, M.G. "Inventory routing problems with multiple customers", EURO Journal on Transportation and Logistics, 2(3), pp. 255-275 (2013).

16. Allahyari, S., Salari, M., and Vigo, D. "A hybrid metaheuristic algorithm for the multi-depot covering tour vehicle routing problem", European Journal of Operational Research, 242(3), pp. 756-768 (2015).

17. Baldacci, R., Mingozzi, A., and Wolfler Calvo, R. "An exact method for the capacitated location-routing problem", Operations Research, 59(5), pp. 1284-1296 (2011).

18. Golmohamadi, S., Tavakkoli-Moghaddam, R., and Hajiaghaei-Keshteli, M. "Solving a fuzzy fixed charge solid transportation problem using batch transferring by new approaches in meta-heuristic", Electronic Notes in Discrete Mathematics, 58, pp. 143-150 (2017).

19. Fathollahi-Fard, A.M., Hajiaghaei-Keshteli, M., Tian, G., and Li, Z. "An adaptive Lagrangian relaxationbased algorithm for a coordinated water supply and wastewater collection network design problem", Information Sciences, 512, pp. 1335-1359 (2020).

20. Min, H. "The multiple vehicle routing problem with simultaneous delivery and pick-up points", Transportation Research Part A: General, 23(5), pp. 377-386 (1989).

21. Salhi, S. and Nagy, G. "A cluster insertion heuristic for single and multiple depot vehicle routing problems with backhauling", Journal of the Operational Research Society, 50(10), pp. 1034-1042 (1999).

22. Nagy, G. and Salhi, S. "Heuristic algorithms for single and multiple depot vehicle routing problems with pickups and deliveries", European Journal of Operational Research, 162(1), pp. 126-141 (2005).

23. Dethloff, J. "Vehicle routing and reverse logistics: the vehicle routing problem with simultaneous delivery and pick-up", OR-Spektrum, 23(1), pp. 79-96 (2001).

24. Gendreau, M., Guertin, F., Potvin, J.Y., and Séguin, R. "Neighborhood search heuristics for a dynamic vehicle dispatching problem with pick-ups and deliveries", Transportation Research Part C: Emerging Technologies, 14(3), pp. 157-174 (2006).

25. Wang, H.F. and Chen, Y.Y. "A genetic algorithm for the simultaneous delivery and pickup problems with time window", Computers \& Industrial Engineering, 62(1), pp. 84-95 (2012).
26. Avci, M. and Topaloglu, S. "A hybrid metaheuristic algorithm for heterogeneous vehicle routing problem with simultaneous pickup and delivery", Expert Systems with Applications, 53, pp. 160-171 (2016).

27. Majidi, S., Hosseini-Motlagh, S.M., and Ignatius, J. "Large neighborhood search heuristic for pollutionrouting problem with simultaneous pickup and delivery", Soft Computing, 22(9), pp. 2851-2865 (2018).

28. Ting, C.K., Liao, X.L., Huang, Y.H., and Liaw, R.T. "Multi-vehicle selective pickup and delivery using metaheuristic algorithms", Information Sciences, 406, pp. 146-169 (2017).

29. Wang, X. and Li, X. "Carbon reduction in the location routing problem with heterogeneous fleet, simultaneous pickup-delivery and time windows", Procedia Computer Science, 112, pp. 1131-1140 (2017).

30. Matos, M.R.S., Frota, Y., and Ochi, L.S. "Green vehicle routing and scheduling problem with split delivery", Electronic Notes in Discrete Mathematics, 69, pp. 13-20 (2018).

31. Abad, H.K.E., Vahdani, B., Sharifi, M., and Etebari, F. "A bi-objective model for pickup and delivery pollution-routing problem with integration and consolidation shipments in cross-docking system", Journal of Cleaner Production, 193, pp. 784-801 (2018).

32. Shi, Y., Boudouh, T., Grunder, O., and Wang, D. "Modeling and solving simultaneous delivery and pickup problem with stochastic travel and service times in home health care", Expert Systems with Applications, 102, pp. 218-233 (2018).

33. Dror, M. and Trudeau, P. "Savings by split delivery routing", Transportation Science, 23(2), pp. 141-145 (1989).

34. Archetti, C., Savelsbergh, M.W., and Speranza, M.G. "Worst-case analysis for split delivery vehicle routing problems", Transportation Science, 40(2), pp. 226-234 (2006).

35. Gulczynski, D., Golden, B., and Wasil, E. "The split delivery vehicle routing problem with minimum delivery amounts", Transportation Research Part E: Logistics and Transportation Review, 46(5), pp. 612626 (2010).

36. Han, A.F.W. and Chu, Y.C. "A multi-start heuristic approach for the split-delivery vehicle routing problem with minimum delivery amounts", Transportation Research Part E: Logistics and Transportation Review, 88, pp. 11-31 (2016).

37. Xia, Y., Fu, Z., Tsai, S.B., and Wang, J. "A new TS algorithm for solving low-Carbon logistics vehicle routing problem with split deliveries by backpack-from a green operation perspective", International Journal of Environmental Research and Public Health, 15(5), p. 949 (2018). 
38. Hernández-Pérez, H., Salazar-González, J.J., and Santos-Hernández, B. "Heuristic algorithm for the split-demand one-commodity pickup-and-delivery travelling salesman problem", Computers \& Operations Research, 97, pp. 1-17 (2018).

39. Qiu, M., Fu, Z., Eglese, R., and Tang, Q. "A tabu search algorithm for the vehicle routing problem with discrete split deliveries and pickups", Computers \& Operations Research, 100, pp. 102-116 (2018).

40. Abdi, A., Abdi, A., Akbarpour, N., Amiri, A.S., and Hajiaghaei-Keshteli, M. "Innovative approaches to design and address green supply chain network with simultaneous pick-up and split delivery", Journal of Cleaner Production, 250, p. 119437 (2020).

41. Amiri, S.A.H.S., Zahedi, A., Kazemi, M., Soroor, J., and Hajiaghaei-Keshteli, M. "Determination of the optimal sales level of perishable goods in a two-echelon supply chain network", Computers \& Industrial Engineering, 139, p. 106156 (2020).

42. Fathollahi-Fard, A.M., Govindan, K., HajiaghaeiKeshteli, M., and Ahmadi, A. "A green home health care supply chain: New modified simulated annealing algorithms", Journal of Cleaner Production, 240, p. 118200 (2019).

43. Fathollahi-Fard, A.M., Hajiaghaei-Keshteli, M., and Mirjalili, S. "A set of efficient heuristics for a home healthcare problem", Neural Computing and Applications, 32(10), pp. 6185-6205 (2020).

44. Feng, Y., Gao, Y., Tian, G., Li, Z., Hu, H., and Zheng, H. "Flexible process planning and end-ofLife decision-making for product recovery optimization based on hybrid disassembly", IEEE Transactions on Automation Science and Engineering, 16(1), pp. 311326 (2018).

45. Tian, G., Zhou, M., and Li, P. "Disassembly sequence planning considering fuzzy component quality and varying operational cost", IEEE Transactions on Automation Science and Engineering, 15(2), pp. 748760 (2017).

46. Tian, G., Ren, Y., Feng, Y., Zhou, M., Zhang, H., and Tan, J. "Modeling and planning for dual-objective selective disassembly using AND/OR graph and discrete artificial bee colony", IEEE Transactions on Industrial Informatics, 15(4), pp. 2456-2468 (2018).

47. Fu, Y., Wang, H., Tian, G., Li, Z., and Hu, H. "Twoagent stochastic flow shop deteriorating scheduling via a hybrid multi-objective evolutionary algorithm", Journal of Intelligent Manufacturing, 30(5), pp. 2257$2272(2019)$.
48. Fu, Y., Tian, G., Fathollahi-Fard, A.M., Ahmadi, A., and Zhang, C. "Stochastic multi-objective modelling and optimization of an energy-conscious distributed permutation flow shop scheduling problem with the total tardiness constraint", Journal of Cleaner Production, 226, pp. 515-525 (2019).

\section{Biographies}

Navid Akbarpour was born in Qaemshahr, Iran. He earned his BSc from Iran University of Science \& Technology, Tehran, Iran (2004) and MSc from Islamic Azad University, Firoozkoh Branch, Iran (2013), all in Industrial Engineering. His main research interests lie in solving combinatorial optimization problems using novel heuristics and metaheuristics. He is interested in developing novel mathematical models in the area of waste management, green supply chain management, and sustainable operations management.

Reza Kia obtained his $\mathrm{PhD}$ in Industrial Engineering in 2013. He was an Assistant Professor at the Industrial Engineering Department, Firoozkooh branch, Islamic Azad University, Iran between the years 2013-2017. Then, he joined the Department of Logistics, Tourism \& Service Management at the German University of Technology in Oman. His research interest is applying simulation-optimization to designing manufacturing and logistics systems.

Mostafa Hajiaghaei-Keshteli was born and raised in Babol, Iran. He earned his BSc from Iran University of Science \& Technology, Tehran, Iran (2004), MSc from University of Science \& Culture, Tehran, Iran (2006), and PhD from Amirkabir University of Technology (Tehran-Polytechnic), Tehran, Iran (2012), all in Industrial Engineering. He is currently a Professor in Industrial Engineering Department at the Tecnologico de Monterrey, Puebla, Mexico. He has over 10 years of experience in business development, system analysis, inventory, and project management. He has worked for many corporations in Iran and has held the positions of consulter, planning and project manager, and VP. The main focus of his research is in the area of inventory control, supply chain network, transportation, and meta-heuristics. He has published more than 100 scientific papers in high-ranking journals such as ESWA, CAIE, KNOSYS, JCLP, NCAA, IEEE, ASOC, etc. 